ARTICLE

\title{
Arsenene-mediated multiple independently targeted reactive oxygen species burst for cancer therapy
}

\author{
Na Kong ${ }^{1}$, Hanjie Zhang ${ }^{2}$, Chan Feng ${ }^{1}$, Chuang Liu', Yufen Xiao ${ }^{1}$, Xingcai Zhang (id ${ }^{3}$, Lin Mei (iD) ${ }^{4}$, \\ Jong Seung Kim (1) ${ }^{5}$, Wei Tao (1) ${ }^{1 凶} \&$ Xiaoyuan Ji (i) ${ }^{1,2 \otimes}$
}

The modulation of intracellular reactive oxygen species (ROS) levels is crucial for cellular homeostasis and determination of cellular fate. A sublethal level of ROS sustains cell proliferation, differentiation and promotes tumor metastasis, while a drastic ROS burst directly induces apoptosis. Herein, surface-oxidized arsenene nanosheets ( $A s / \mathrm{As}_{\mathrm{x}} \mathrm{O}_{\mathrm{y}} \mathrm{NSs}$ ) with type II heterojunction are fabricated with efficient $\mathrm{O}_{2}{ }^{-}$and ${ }^{1} \mathrm{O}_{2}$ production and glutathione consumption through prolonging the lifetime of photo-excited electron-hole pairs. Moreover, the portion of $\mathrm{As}_{x} \mathrm{O}_{y}$ with oxygen vacancies not only catalyzes a Fenton-like reaction, generating . $\mathrm{OH}$ and $\mathrm{O}_{2}$ from $\mathrm{H}_{2} \mathrm{O}_{2}$, but also inactivates main anti-oxidants to cut off the "retreat routes" of ROS. After polydopamine (PDA) and cancer cell membrane (M) coating, the engineered As/As $\mathrm{O}_{\mathrm{y}} @ P D A @ M$ NSs serve as an intelligent theranostic platform with active tumor targeting and long-term blood circulation. Given its narrow-band-gap-enabled in vivo fluorescence imaging properties, As/As $\mathrm{O}_{\mathrm{y}} @ P D A @ M$ NSs could be applied as an imaging-guided non-invasive and real-time nanomedicine for cancer therapy.

\footnotetext{
${ }^{1}$ Center for Nanomedicine, Brigham and Women's Hospital, Harvard Medical School, Boston, MA, USA. ${ }^{2}$ Academy of Medical Engineering and Translational Medicine, Medical College, Tianjin University, Tianjin, China. ${ }^{3}$ School of Engineering and Applied Sciences, Harvard University, Cambridge, MA, USA.

${ }^{4}$ Tianjin Key Laboratory of Biomedical Materials, Key Laboratory of Biomaterials and Nanotechnology for Cancer Immunotherapy, Institute of Biomedical Engineering, Chinese Academy of Medical Sciences and Peking Union Medical College, Tianjin, China. ${ }^{5}$ Department of Chemistry, Korea University,

Seoul, Korea. $\varpi_{\text {email: wtao@bwh.harvard.edu; jixiaoyuan@tju.edu.cn }}$
} 
eactive oxygen species (ROS) are a group of highly reactive small molecules generated by all aerobic organisms, which include hydroxyl radicals $(\cdot \mathrm{OH})$, superoxide $\left(\cdot \mathrm{O}_{2}{ }^{-}\right)$, and other nonradical members such as hydrogen peroxide $\left(\mathrm{H}_{2} \mathrm{O}_{2}\right)$ and singlet oxygen $\left({ }^{1} \mathrm{O}_{2}\right)^{1,2}$. In particular, the redox balance of ROS between oxidizing and reducing species, through the cooperation of various enzymes (e.g., catalase, glutathione peroxidase and superoxide dismutase), is important in cell growth, proliferation, and signaling pathways ${ }^{3-6}$. However, the overproduction of ROS can cause oxidative stress, leading to cellular damage as well as the subsequent functional decline of organ systems ${ }^{7}$.

Although cancer cells are under higher oxidative stress because of the disrupted ROS homeostasis, they have adapted themselves to the overproduced ROS by activating antioxidant systems (e.g., the upregulation of glutathione, GSH $)^{4,8}$. Ironically, they can utilize ROS to drive other events required for tumor development ${ }^{1,3}$. Hence, the modulation of intracellular ROS levels is crucial for tumor cellular homeostasis and determination of cellular fate, as different concentrations and durations of ROS stress can induce distinct biological responses. Therefore, only a powerful ROS burst to induce a high ROS level can cause effective cellular damage and apoptotic cell death.

Recently, a number of efforts have been devoted in chemodynamic therapy (CDT), photodynamic therapy (PDT), sonodynamic therapy (SDT) and other strategies to specifically increase the ROS level in cancer cells to mediate cell death ${ }^{9-11}$. However, to achieve a sufficient ROS burst, high concentrations of photo-/ sono-sensitizers, high excitation energy, or harsh reaction environment are essential, which would in turn easily trigger adverse effects in normal tissues ${ }^{7}$. Therefore, elevating oxidative stress by multipartite generation of ROS preferentially in cancer cells with a low dose of sensitizers, lower excitation energy requirement, and simultaneous blockage of the ROS consumption pathway would be a logical and ideal therapeutic strategy. However, achieving the above-mentioned goal remains a critical bottleneck.

Two-dimensional (2D) nanomaterials with extraordinary physicochemical properties have attracted extensive attention for exciting applications in energy, catalysis, electronics, and biomedicines ${ }^{12-17}$. Driven especially by excellent optical and electronic properties and outstanding biocompatibility, monoelemental 2D materials (e.g., borophene, phosphorene, antimonene, and germanene) have been developed as promising anticancer therapeutics: photosensitizers (PSs) for PDT and photothermal therapy (PTT), nano-carriers for drug delivery, as well as multi-modal imaging agents ${ }^{18-25}$. As an element in the same family of phosphorus, arsenene with its layered structure has recently been demonstrated to have characteristics similar to those of the buckled honeycomb structure of phosphorene and antimonene ${ }^{26,27}$. Owing to its suitably moderate band structure, high carrier mobility, as well as good optical properties, arsenene has been regarded as a promising candidate for photocatalysis, electrocatalysis, semiconducting devices, etc. ${ }^{28,29}$. Despite this substantial promise, not much efforts have been made to develop biomedical applications of arsenene ${ }^{30,31}$, especially its potential in cancer photonic therapies, such as PDT and PTT. Very recently, Wang and co-workers successfully synthesized arsenene nanosheet and applied it in an anticancer study, in which arsenene showed specific cytotoxicity against NB4 promyelocytic leukemia cells through affecting nuclear DNA replication, nucleotide excision repair, and pyrimidine metabolism pathways by downregulating the DNA polymerases (e.g., POLE, POLD1, POLD2, and POLD3 $)^{32}$. More importantly, considering that arsenic trioxide $\left(\mathrm{As}_{2} \mathrm{O}_{3}\right)$ has now been approved by the U.S. Food and Drug Administration (FDA) as a frontline remedy for acute promyelocytic leukemia $(\mathrm{APL})^{33,34}$, arsenene has been subjected to extensive pharmacological and clinical analysis, holds great promise for biomedical applications.

Herein, we designed and fabricated a type II heterojunction photocatalyst based on arsenene, which is capable of multiple independently targeted ROS bursts but requiring a low-dose administration and less excitation energy. As shown in Fig. 1, by coupling ball-grinding with probe sonication-based liquid exfoliating processes, arsenene nanosheets with partial surface oxidation of As (As/ $\mathrm{As}_{x} \mathrm{O}_{y}$ NSs) constructed type II heterojunction were synthesized. The photo-excited electrons in the conduction band $(\mathrm{CB})$ of As can be transferred to the $\mathrm{CB}$ of $\mathrm{As}_{x} \mathrm{O}_{y}$ to catalyze the generation of $\cdot \mathrm{O}_{2}{ }^{-}$from $\mathrm{O}_{2}$, while the holes in the valence band (VB) of $\mathrm{As}_{x} \mathrm{O}_{y}$ can be transferred to the VB of As to promote the oxidation of GSH. This type II heterojunction structure retards recombination of photogenerated electron-hole pairs of As/ $\mathrm{As}_{x} \mathrm{O}_{y}$ NSs, which provides maximal power to catalyze the generation of ROS from $\mathrm{O}_{2}$ on the one hand, while blocking the consumption of ROS by GSH on the other hand. Additionally, the As in $\mathrm{As} / \mathrm{As}_{x} \mathrm{O}_{y}$ NSs could generate ${ }^{1} \mathrm{O}_{2}$ through energy conversion, and the $\mathrm{As}_{x} \mathrm{O}_{y}$ in $\mathrm{As} / \mathrm{As}_{x} \mathrm{O}_{y}$ NSs could inactivate some main anti-oxidants and anti-oxidases containing sulfhydryl groups to cut off the "retreat routes" of ROS. Moreover, the oxygen vacancies in $\mathrm{As} / \mathrm{As}_{x} \mathrm{O}_{y}$ NSs not only catalyze the disproportionate reaction of $\mathrm{H}_{2} \mathrm{O}_{2}$ via the high reduction ability of As ${ }^{\text {III }}$, but also generate $\mathrm{O}_{2}$ through $\mathrm{H}_{2} \mathrm{O}_{2}$ oxidation via the high oxidation capability of $\mathrm{As}^{\mathrm{V}}$. Hence, the prepared $\mathrm{As} / \mathrm{As}_{x} \mathrm{O}_{y} \mathrm{NSs}$ can mediate synergetic tripartite ROS generation and block two main ROS consumption pathways, producing a dramatic ROS burst. In addition, its efficient photothermal conversion ability under $808 \mathrm{~nm}$ laser irradiation alongside its intrinsic fluorescence properties further enriched the biomedical applications of As/ $\mathrm{As}_{x} \mathrm{O}_{y}$ NSs. With the aid of surface engineering using polydopamine (PDA) and cancer cell membrane (M) coating, the obtained As/As $\mathrm{O}_{y} @ P D A @ M$ NSs possess the advantages of a long blood circulation time, active cancer cell targeting, and tumor micro-environment (TME) responsive degradation, constituting excellent potential for in vivo fluorescence imagingguided non-invasive and real-time cancer therapy.

In line of the revealed complete elimination of tumors without recurrence, our work presents arsenene-based nanomedicine with multiple independently targeted ROS bursts for effective cancer therapy. We also anticipate the appearance of such heterojunction photocatalysts will be attractive in other settings beyond biomedical applications.

\section{Results}

Fabrication and characterization of As/As $\mathrm{O}_{y} @ \mathrm{PDA} @ \mathrm{M}$ Ns. The synthesis of 2D ultrathin As/As $\mathrm{O}_{y} @ \mathrm{PDA} @ \mathrm{M}$ NSs is illustrated in Fig. 1, in which ball-grinding and liquid exfoliation were employed, and further PDA and cancer cell membrane coating were performed. In detail, layered As powder (Supplementary Fig. 1) with planar size about $5 \mu \mathrm{m}$ immersed in $\mathrm{N}$ methyl-2-pyrrolidone (NMP) solution was ground in a ball grinder, and As particles with planar size $<1 \mu \mathrm{m}$ were obtained. Next, the ground As powder dispersed in NMP was subjected to ultrasonic-assisted liquid exfoliation for $12 \mathrm{~h}$. Surface-oxidized ultrathin As NSs $\left(\mathrm{As} / \mathrm{As}_{x} \mathrm{O}_{y} \mathrm{NSs}\right)$ were obtained with an average size of $93 \mathrm{~nm}$ and thickness of $3 \mathrm{~nm}$, according to their TEM and AFM images, respectively (Fig. 2a, f, and Supplementary Fig. 2). To further confirm the successful fabrication of $\mathrm{As} / \mathrm{As}_{x} \mathrm{O}_{y} \mathrm{NSs}$ heterojunction, X-ray diffractometry (XRD), Raman detection, and X-ray photoelectron spectroscopy (XPS) were performed. Figure 3a showed the typical Raman spectra of the bulk As and the as-prepared As/As $\mathrm{O}_{y}$ NSs with two peaks at 258 and $196 \mathrm{~cm}^{-1}$, which are consistent with the $A_{1 g}$ (out-of-plane vibration) and $E_{g}$ 


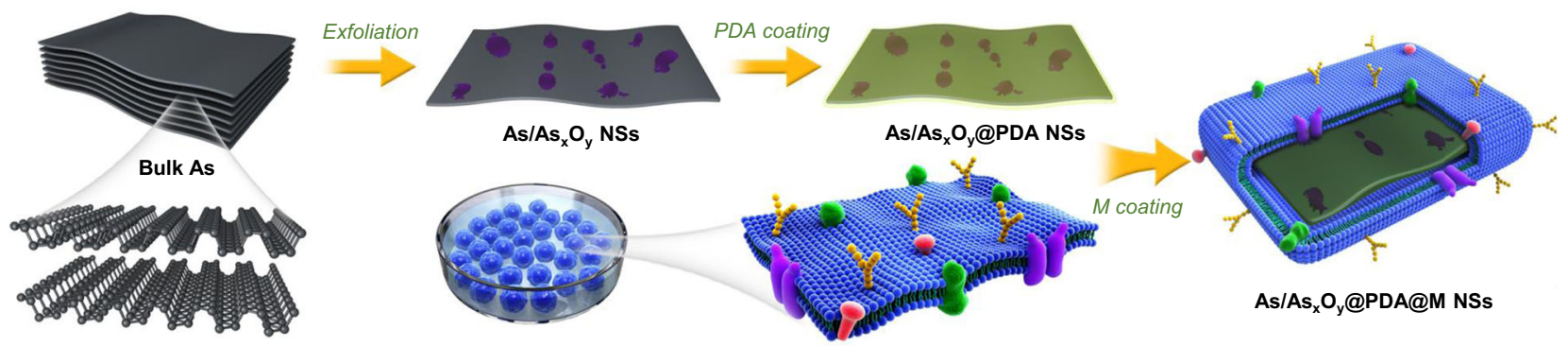

Cancer cell membrane extraction (M)
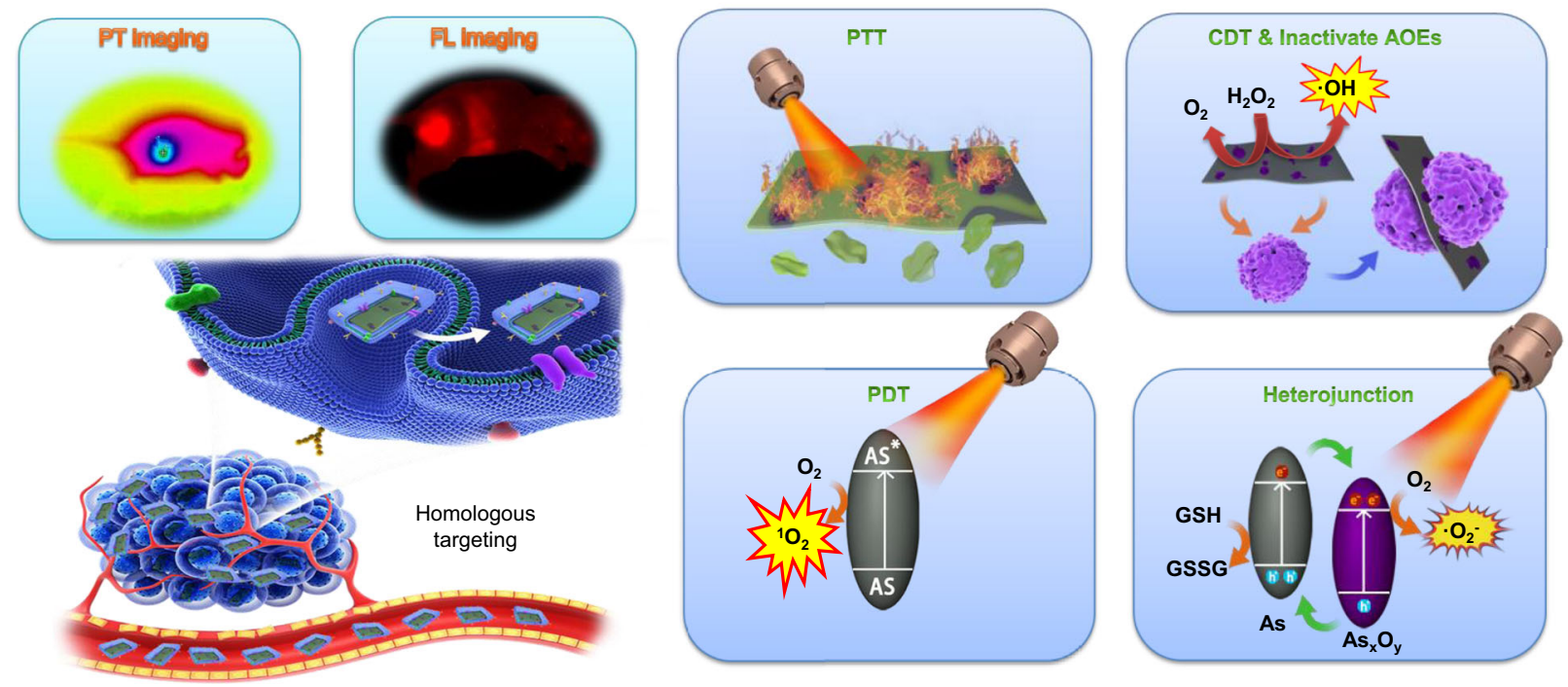

Fig. 1 Schematic illustration of preparation and dual-modal imaging-guided cancer theranostics using As/As $\mathbf{O}_{\mathbf{y}} @$ PDA@M NSs. Surface-oxidized arsenene nanosheets $\left(\mathrm{As} / \mathrm{As}_{x} \mathrm{O}_{y} \mathrm{NSs}\right.$ ) with type II heterojunction were fabricated by ball-grinding and liquid exfoliation. After polydopamine (PDA) and

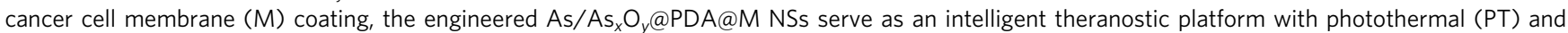
fluorescence imagings guided photothermal therapy (PTT), photodynamic therapy (PDT), chemodynamic therapy (CDT), and inactivate antioxidant enzymes (AOEs).

(in-plane vibration) modes of arsenic, respectively ${ }^{32}$. In addition, a broadband of amorphous arsenic with weak intensity at 200-260 $\mathrm{cm}^{-1}$ was observed attributing to the formation of $\mathrm{As}_{x} \mathrm{O}_{y}$ on the surface of As $\mathrm{NSs}^{35}$, which indicated the amorphization of arsenene after exfoliation.

$\mathrm{XRD}$ detection of $\mathrm{As} / \mathrm{As}_{x} \mathrm{O}_{y} \mathrm{NSs}$ (Fig. 3b) further demonstrated successful heterojunction functionalization, in which three respective structures corresponding with As (JCPDS No. 00001-0760), $\mathrm{As}_{2} \mathrm{O}_{3}$ (JCPDS No. 00-001-0754), and $\mathrm{As}_{2} \mathrm{O}_{5}$ (JCPDS No. 00-001-0260) were observed. In the XPS analysis (Fig. $3 \mathrm{c}$ ), the peak intensity of $\mathrm{O}$ from the XPS spectrum of As/As $\mathrm{O}_{y}$ NSs was much higher than that of bulk As powder, which should be ascribed to the result of surface oxidation. As shown in Fig. 3d, the typical As $3 d$ high-resolution XPS spectra of metallic As were made up of two peaks at 42.3 and $41.6 \mathrm{eV}$, which were attributed to As $3 d_{3 / 2}$ and As $3 d_{5 / 2}$, respectively ${ }^{36}$. Notably, two other peaks at about 45 and $45.5 \mathrm{eV}$, in accordance with the $\mathrm{As}^{3+}\left(\mathrm{As}^{\mathrm{III}}\right)$ and $\mathrm{As}^{5+}\left(\mathrm{As}^{\mathrm{V}}\right)$ of As-O, respectively, were displayed in the As $3 d$ high-resolution XPS spectra, which further confirmed the formation of $\mathrm{As} / \mathrm{As}_{x} \mathrm{O}_{y}$ NSs. Additionally, the co-existence of the lattice fringes of As (Fig. 2b) and some amorphism of $\mathrm{As}_{x} \mathrm{O}_{y}$ (Fig. 2c) in $\mathrm{As} / \mathrm{As}_{x} \mathrm{O}_{y}$ NSs also confirmed the successful fabrication of the heterojunction structure.

To improve the stability and photothermal conversion performance of $\mathrm{As} / \mathrm{As}_{x} \mathrm{O}_{y}$ NSs, a PDA shell was introduced by self-polymerization of dopamine to form As/As $\mathrm{O}_{y} @ \mathrm{PDA}$ NSs. After PDA coating, the average size and thickness of As/
$\mathrm{As}_{x} \mathrm{O}_{y} @ \mathrm{PDA}$ NSs increased to 141 and 7 nm, respectively (Fig. 2d, $\mathrm{g}$ and Supplementary Fig. 2). To further achieve a good biocompatibility with initiative targeting ability, the As/ $\mathrm{As}_{x} \mathrm{O}_{y} @ \mathrm{PDA} \mathrm{NSs}$ were further engineered to incorporate cancer cell membrane through an ultrasonic-assisted self-assembly strategy to form As/As $\mathrm{O}_{y} @ \mathrm{PDA} @ \mathrm{M}$ Ns. The successful deposition of cell membrane coating on the surface of As/ $\mathrm{As}_{x} \mathrm{O}_{y} @ \mathrm{PDA} \mathrm{NSs}$ was clearly confirmed by TEM images of an obvious coating layer (Fig. 2e). Also, the planar size and thickness of As/As $\mathrm{O}_{y} @ \mathrm{PDA} @ M$ NSs increased to $156 \mathrm{~nm}$ (Supplementary Fig. 2) and $10 \mathrm{~nm}$ (Fig. 2h), respectively. Additionally, the membrane proteins from the cell membrane were well retained during this process (Supplementary Fig. 3). Moreover, XPS test indicated three new peaks of $\mathrm{C}, \mathrm{N}$, and $\mathrm{P}$ were present in As/ $\mathrm{As}_{x} \mathrm{O}_{y} @ \mathrm{PDA} @ \mathrm{M}$ NSs (Fig. 3c), which could be attributed to the PDA and M. Moreover, the elements As, C, N, O, and P were presented in the EDS mapping of $\mathrm{As} / \mathrm{As}_{x} \mathrm{O}_{y} @ \mathrm{PDA} @ \mathrm{NS}$ (Fig. 2i), and the zeta potential of differently functionalized As/ $\mathrm{As}_{x} \mathrm{O}_{y}$ NSs (Supplementary Fig. 4) further demonstrated the successful surface coating of PDA and M shells.

Characterization and analysis of mechanism underlying ROS burst ability. The deconvoluted As $3 d$ spectra of $A s / \mathrm{As}_{x} \mathrm{O}_{y}$ NSs presented two peaks at 45 and $45.5 \mathrm{eV}$, which were in line with the binding energy of $\mathrm{As}^{3+}\left(\mathrm{As}_{2} \mathrm{O}_{3}\right)$ and $\mathrm{As}^{5+}\left(\mathrm{As}_{2} \mathrm{O}_{5}\right)$, respectively. In addition, compared with bulk As, the binding energies 

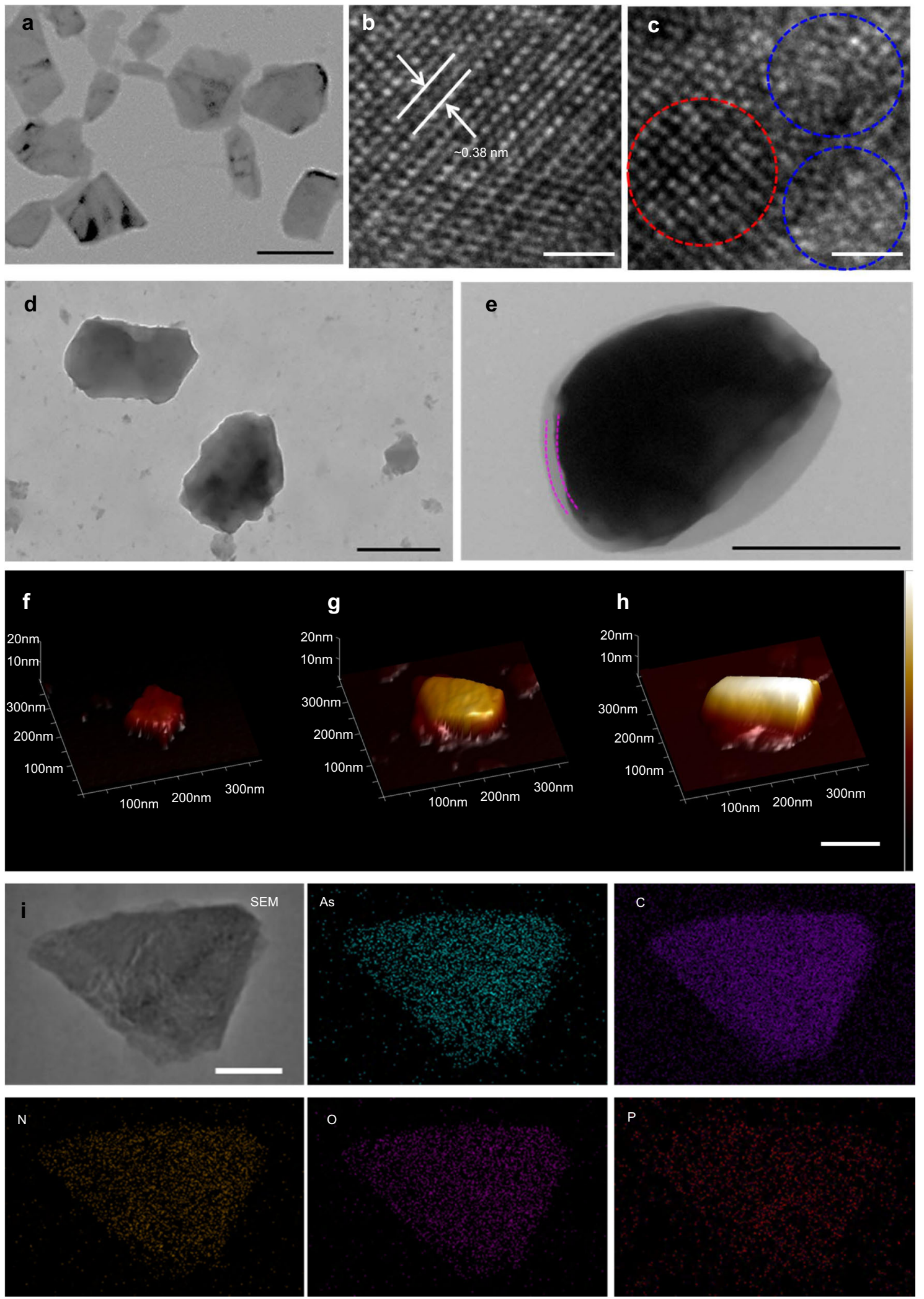

Fig. 2 Morphology and composition characterization of ultrathin 2D As/As $\mathbf{s}_{\mathbf{x}} \mathbf{O}_{\mathbf{y}} @ \mathbf{P D A} @ \mathbf{M}$ NSs. a TEM images of $A s / A s_{x} \mathrm{O}_{y} \mathrm{NSs}, \mathrm{scale} b a r=100 \mathrm{~nm}$. b HRTEM images of As NSs, scale bar $=1 \mathrm{~nm}$. c HRTEM images of $A s / A_{x} \mathrm{O}_{y}$ NSs (red circle: lattice fringes of As; blue circle: amorphism of $A s_{x} O_{y}$ ), scale bar=1nm. d TEM images of As/As $\mathrm{O}_{y} @ P D A$ NSs, scale bar=100 nm. e TEM images of As/As $\mathrm{O}_{y} @ P D A @ M ~ N S s, ~ s c a l e ~ b a r=100$ nm. f-h AFM images

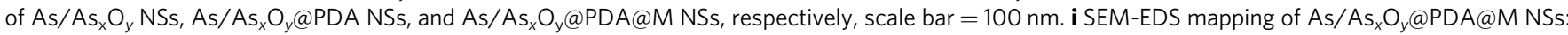
green $(A s)$, purple $(C)$, orange $(N)$, pink $(O)$, and red $(P)$, scale bar $=50 \mathrm{~nm}$. For these morphology characterizations of fabricated As-based NSs, three times each experiment was repeated independently with similar results. 


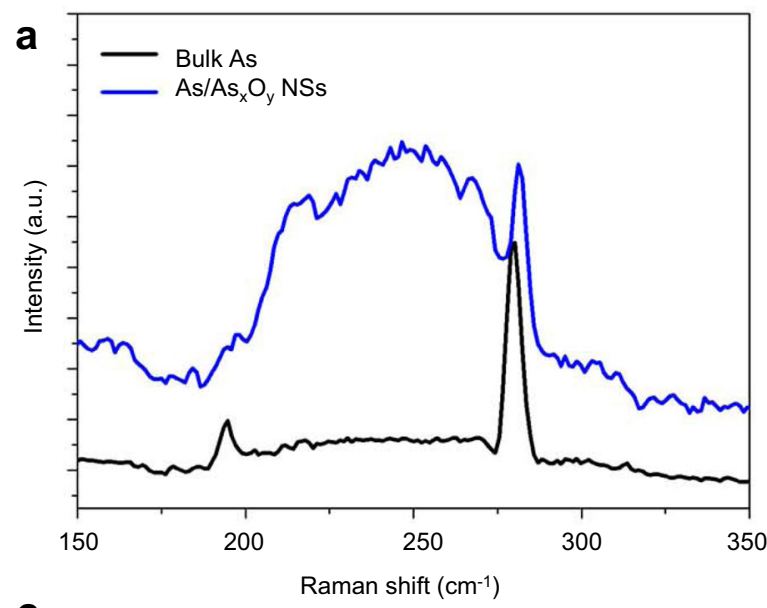

C

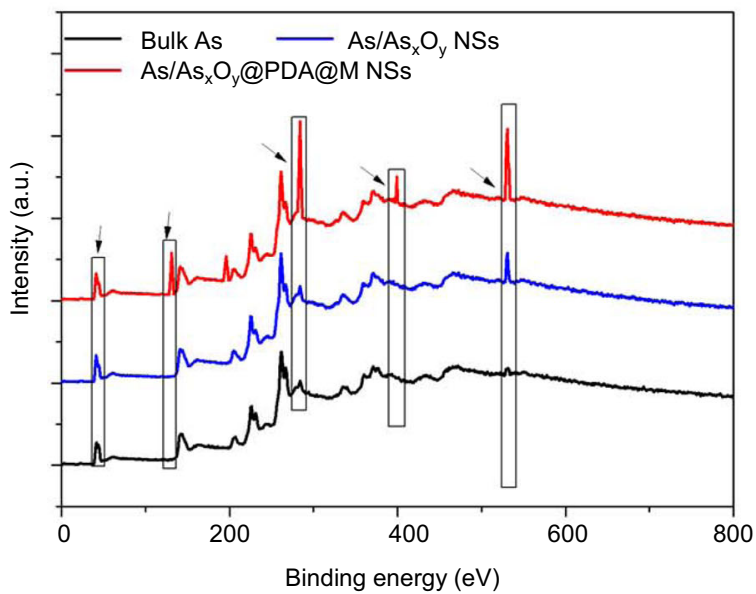

e

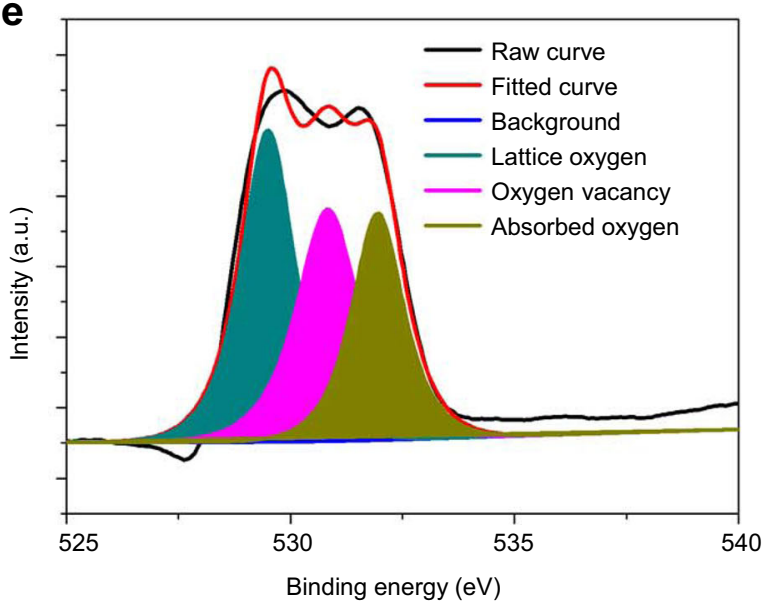

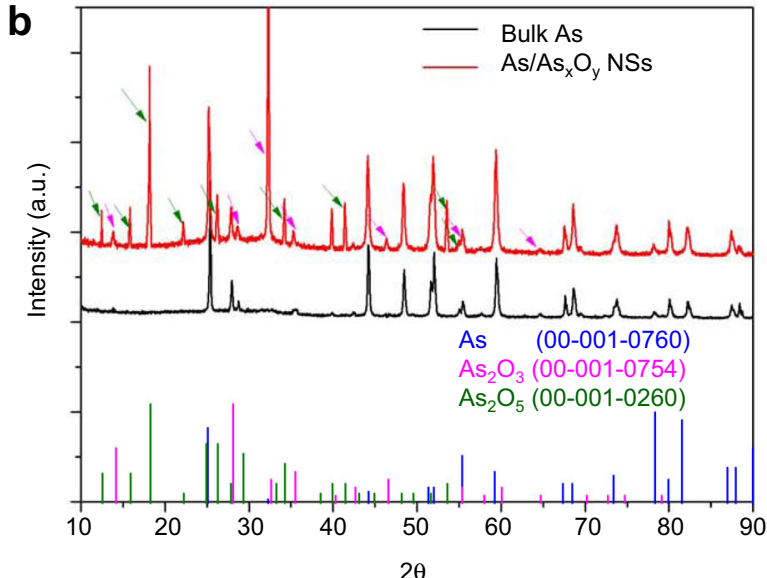

d

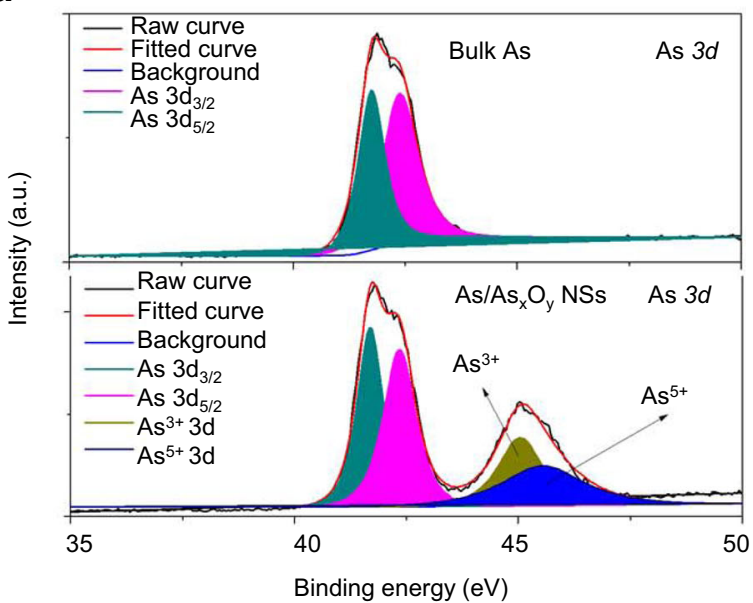

f

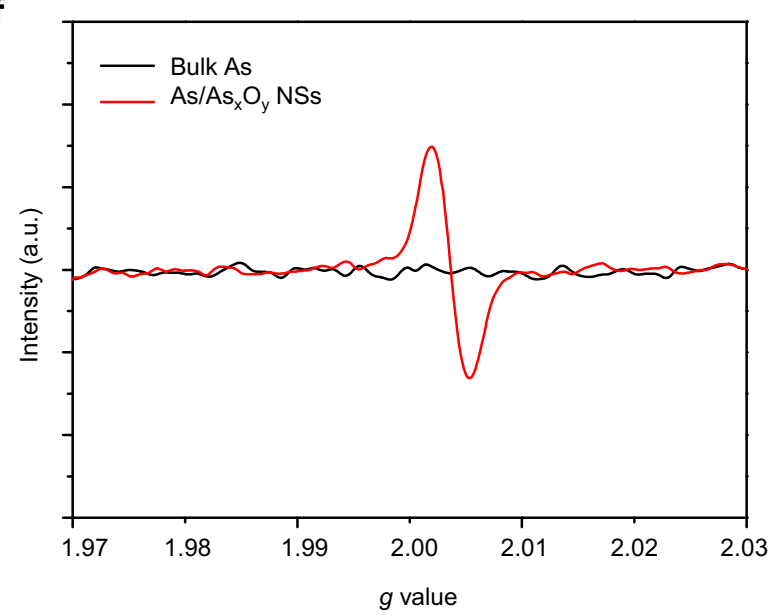

Fig. 3 Chemical composition and structure characterization of ultrathin 2D As/As $\mathbf{O}_{\mathbf{y}} @ \mathbf{P D A} @ \mathbf{M}$ NSs. a Raman shift spectra of bulk As and As/As $\mathrm{O}_{\boldsymbol{y}}$ NSs. $\mathbf{b}$ XRD spectra of bulk As and $A s / A s_{x} O_{y}$ NSs. c XPS spectra of bulk As, As/As $\mathrm{O}_{y}$ NSs, and $A s / A s_{x} O_{y} @ P D A @ M$ NSs. d HRXPS spectra of As $3 d$ in bulk $A s$ and $A s / A s_{x} O_{y}$ NSs. e HRXPS spectra of $\mathrm{O} 1 s$ in bulk $A s$ and $A s / A s_{x} O_{y}$ NSs. $\mathbf{f}$ ESR spectra of bulk $A s$ and $A s / A s_{x} O_{y} N S s$. For these chemical characterizations of fabricated As based NSs, three times each experiment was repeated independently with similar results.

of $3 d$ As in As $/ \mathrm{As}_{x} \mathrm{O}_{y}$ NSs was lower, which might be ascribed to the introduction of oxygen vacancy into As/As $\mathrm{O}_{y}$ NSs. To confirm the formation of oxygen vacancy on the surface of As/ $\mathrm{As}_{x} \mathrm{O}_{y}$ NSs, HRXPS and EPR measurements were employed. As shown in the $\mathrm{O} 1 s$ scans (Fig. 3e), there were three $\mathrm{O}$ species attributed to lattice oxygen (e.g., $\mathrm{As}_{2} \mathrm{O}_{3}$ and $\mathrm{As}_{2} \mathrm{O}_{5}$ ) in the surface of As/ $\mathrm{As}_{x} \mathrm{O}_{y}$ NSs $(529.5 \mathrm{eV})$, oxygen vacancies $(530.5 \mathrm{eV})$, and absorbed oxygen on the surface of samples $(532.2 \mathrm{eV})$. To analyze the trapped electrons in As samples, ESR spectroscopy was carried out (Fig. 3f). Bulk As showed weak ESR signals, indicating a very low percentage of defects. By contrast, the as-exfoliated As/ $\mathrm{As}_{x} \mathrm{O}_{y}$ NSs exhibited a symmetrical pair of peaks, attributable to the trapped unpaired electrons from the oxygen vacancies that adsorbed oxygen species from air. As is well-known, numerous metallic oxides with oxygen-deficient structures exhibit excellent behaviors in the fields of catalysis and energy conversion ${ }^{37,38}$. Herein, methylene blue (MB) was employed to study $\cdot \mathrm{OH}$ generation ability through Fenton-like reactions between $\mathrm{As} / \mathrm{As}_{x} \mathrm{O}_{y}$ 

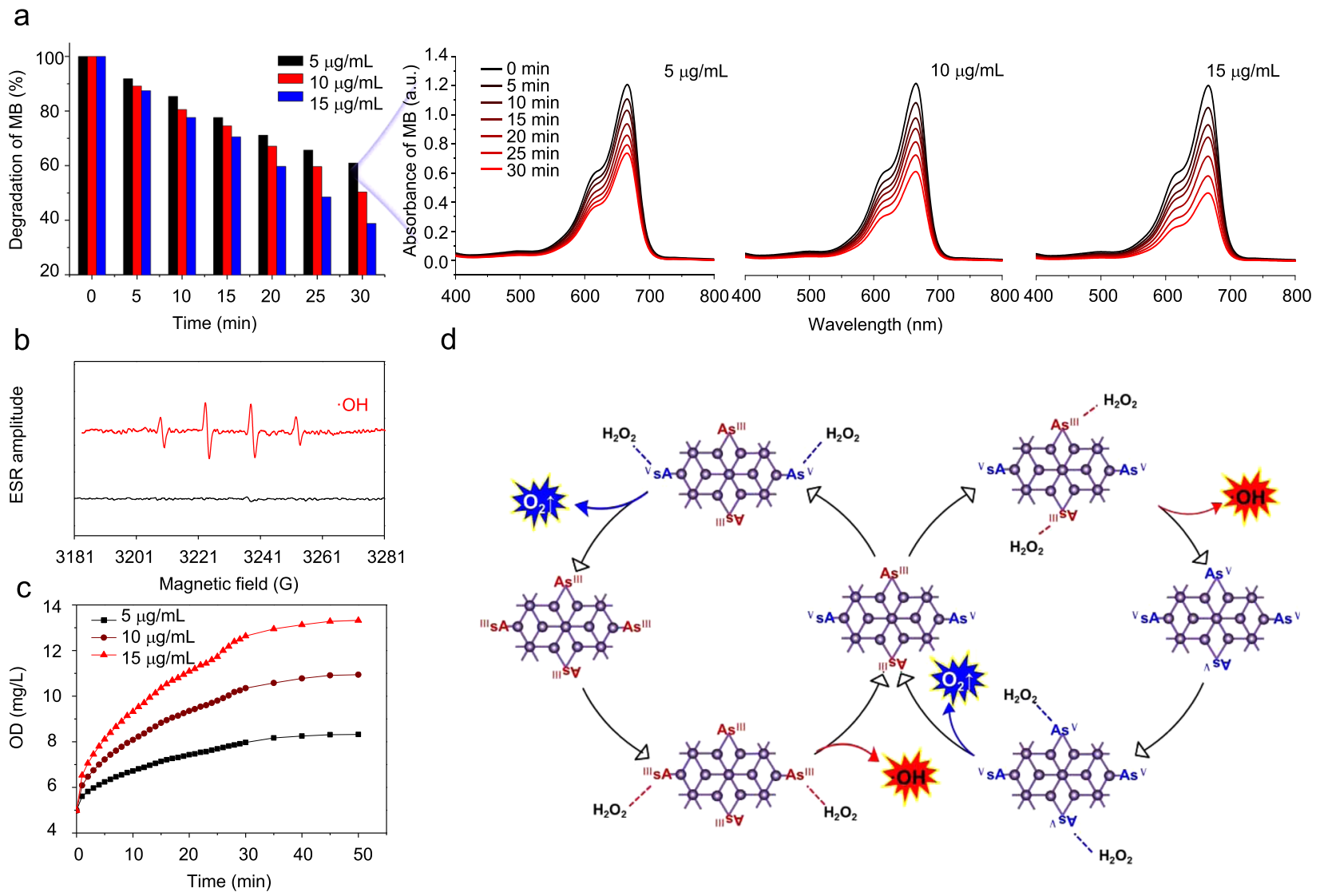

Fig. 4 Fenton-like reaction-catalyzed ability of $\mathbf{A s} / \mathbf{A s}_{\mathbf{x}} \mathbf{O}_{\mathbf{y}} \mathbf{N S s}$. a Degradation of $\mathrm{MB}$ caused by the generation of $\cdot \mathrm{OH}$ with different concentration of $\mathrm{As} /$ $\mathrm{As}_{x} \mathrm{O}_{y} \mathrm{NSs}(5-15 \mu \mathrm{g} / \mathrm{mL})$. b ESR spectra of $\cdot \mathrm{OH}$ generated by $\mathrm{As} / \mathrm{As}_{x} \mathrm{O}_{y} \mathrm{NSs} . \mathbf{c} \mathrm{O}_{2}$ generation by $\mathrm{As} / \mathrm{As}_{x} \mathrm{O}_{y} \mathrm{NSs}$ at different concentrations (5-15 $\mu \mathrm{g} / \mathrm{mL}$ ). d The mechanism of $\mathrm{As} / \mathrm{As}_{x} \mathrm{O}_{y} \mathrm{NSs}$ for generation of $\cdot \mathrm{OH}$ and $\mathrm{O}_{2}$. As ${ }^{\prime \prime \prime}$ with high reducibility catalyzes the disproportionate reaction of $\mathrm{H}_{2} \mathrm{O}_{2}$ to generate

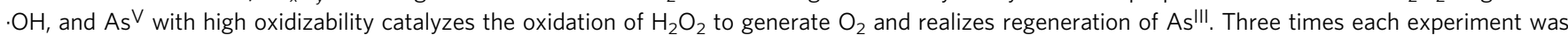
repeated independently with similar results.

NSs and $\mathrm{H}_{2} \mathrm{O}_{2}{ }^{39}$. Figure $4 \mathrm{a}$ presented the degradation of MB under different concentrations of $\mathrm{As} / \mathrm{As}_{x} \mathrm{O}_{y}$ NSs in the presence of $\mathrm{H}_{2} \mathrm{O}_{2}$. Considerable $\mathrm{MB}$ degradation was observed with the increased concentrations of $A s / \mathrm{As}_{x} \mathrm{O}_{y}$ NSs. Moreover, ESR measurements further confirmed the generation of $\cdot \mathrm{OH}$ via Fentonlike reactions catalyzed by the $\mathrm{As} / \mathrm{As}_{x} \mathrm{O}_{y}$ NSs with plenty of oxygen vacancies (Fig. 4b). Obvious $\mathrm{O}_{2}$ generation was also observed (Fig. 4c), which could not only relieve the hypoxic microenvironment in the tumor, but also enhance the efficiency of PDT mediated by As $/ \mathrm{As}_{x} \mathrm{O}_{y}$ NSs. The mechanism of As/As $\mathrm{O}_{y}$ NSs-mediated Fenton-like reactions for the generation of $\cdot \mathrm{OH}$ and $\mathrm{O}_{2}$ was explained in Fig. 4d. In detail, after exfoliationassisted surface oxidation, $\mathrm{As}_{2} \mathrm{O}_{3}$ and $\mathrm{As}_{2} \mathrm{O}_{5}$ were found on the surface of $\mathrm{As} / \mathrm{As}_{x} \mathrm{O}_{y}$ NSs. Abundant oxygen vacancies were detected on the surface of $A s / \mathrm{As}_{x} \mathrm{O}_{y} \mathrm{NSs}$, which could not only catalyze the disproportionate reaction of $\mathrm{H}_{2} \mathrm{O}_{2}$ via the high reduction ability of $\mathrm{As}{ }^{\mathrm{III}}$, but also generate $\mathrm{O}_{2}$ through $\mathrm{H}_{2} \mathrm{O}_{2}$ oxidation by the high oxidation ability of $\mathrm{As}^{\mathrm{V}}$. As a consequence, the Fenton-like reaction enables the $\mathrm{As} / \mathrm{As}_{x} \mathrm{O}_{y}$ NSs to produce .OH (one of most toxic ROS), and to relieve the hypoxic tumor microenvironment by self-generation of $\mathrm{O}_{2}$, which further served as a substrate for enhancing PDT.

Next, the performance of $A s / \mathrm{As}_{x} \mathrm{O}_{y}$ NSs as an efficient photosensitizer for inducing ROS burst was investigated in depth. As shown in Fig. 5a, an obvious degradation of 1,3-diphenylisobenzofuran (DPBF) was observed after the treatment of As/ $\mathrm{As}_{x} \mathrm{O}_{y}$ NSs at a low concentration $(5-15 \mu \mathrm{g} / \mathrm{mL})$ plus $660 \mathrm{~nm}$ laser irradiation even under a low power density $\left(0.3 \mathrm{~W} \mathrm{~cm}^{-2}\right)$, which demonstrated the ROS generation from $\mathrm{O}_{2}$ under the strong catalyzing effect of $\mathrm{As} / \mathrm{As}_{x} \mathrm{O}_{y}$ NSs. More interestingly, GSH oxidation was also noted in case of $A s / A_{x} \mathrm{O}_{y}$ NSs plus $660 \mathrm{~nm}$ laser irradiation (Fig. 5b), which indicated that $\mathrm{As} / \mathrm{As}_{x} \mathrm{O}_{y}$ NSs could catalyze both the reduction of $\mathrm{O}_{2}$ and oxidation of GSH, inducing ROS aggregation directly and indirectly, respectively.

For a detailed analysis of the type of ROS, ESR was employed by using 5,5-dimethyl-1-pyrrolineN-oxide as a spin trapping agent. Interestingly, two types of $\operatorname{ROS}\left(\cdot \mathrm{O}_{2}^{-}\right.$and $\left.{ }^{1} \mathrm{O}_{2}\right)$ were detected (Fig. 5c). The mechanism for the generation of ${ }^{1} \mathrm{O}_{2}$ was similar to that of black phosphorus (BP) NSs and most organic small molecule photosensitizers, which should be ascribed to the absorbed light energy transferred to $\mathrm{O}_{2}$ and mediated by As NSs. To further confirm the mechanism of GSH depletion and $\cdot \mathrm{O}_{2}{ }^{-}$ generation of $\mathrm{As} / \mathrm{As}_{\mathrm{x}} \mathrm{O}_{\mathrm{y}} \mathrm{NSs}$ under $660 \mathrm{~nm}$ laser irradiation, XPS spectra and solid UV-vis-NIR absorbance spectra of the As/ $\mathrm{As}_{x} \mathrm{O}_{y}$ NSs were measured to reveal their electronic band structure. Figure $5 \mathrm{~d}$ demonstrates that the prepared $\mathrm{As} / \mathrm{As}_{x} \mathrm{O}_{y}$ NSs have a much stronger light-absorbance ability than bulk As. As shown in Fig. 5d, two curves resulting from the heterogeneous structure of $\mathrm{As} / \mathrm{As}_{x} \mathrm{O}_{y}$ NSs were observed, and the band gaps $\left(E_{\mathrm{g}}\right)$ of $A s$ and $A s_{x} \mathrm{O}_{y}$ in $A s / A s_{x} \mathrm{O}_{y}$ NSs were calculated to be 1.4 and $1.7 \mathrm{eV}$, respectively. Similarly, from the XPS spectra, the VB values of $A s$ and $\mathrm{As}_{x} \mathrm{O}_{y}$ of $A s / \mathrm{As}_{x} \mathrm{O}_{y}$ NSs were calculated to be 0.4 and $1.2 \mathrm{eV}$, respectively (Fig. 5e). Next, from the difference between $\mathrm{Eg}$ and $\mathrm{VB}$, the $\mathrm{CB}$ values of $\mathrm{As}$ and $\mathrm{As}_{x} \mathrm{O}_{y}$ were determined to be -1.0 and $-0.5 \mathrm{eV}$, respectively. The energy bands and electron transfer in $\mathrm{As} / \mathrm{As}_{x} \mathrm{O}_{y}$ NSs are presented in 

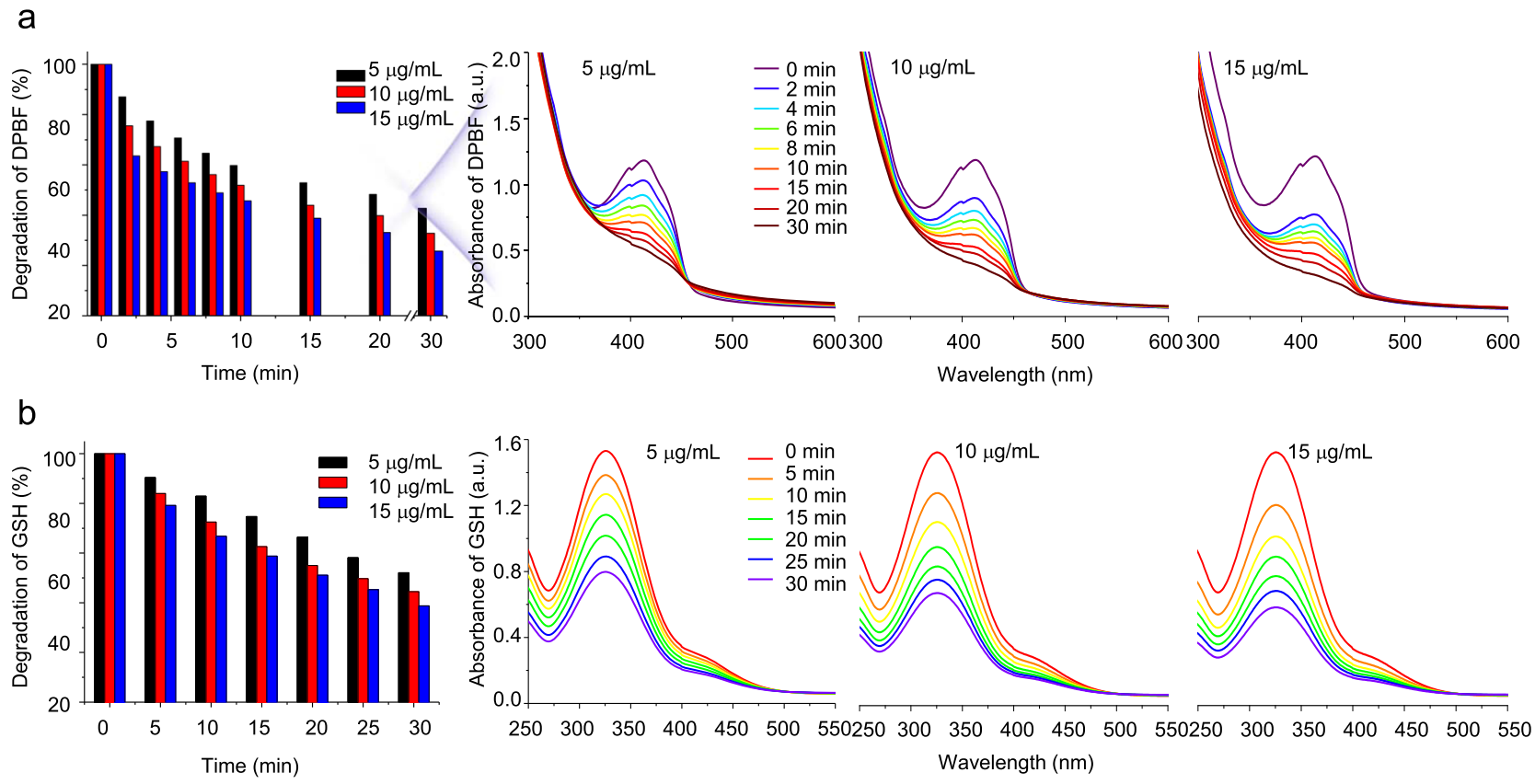

C

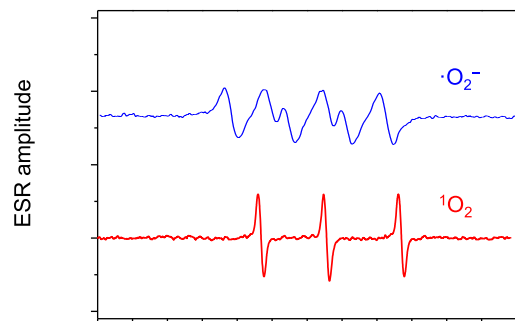

Magnetic field (G)

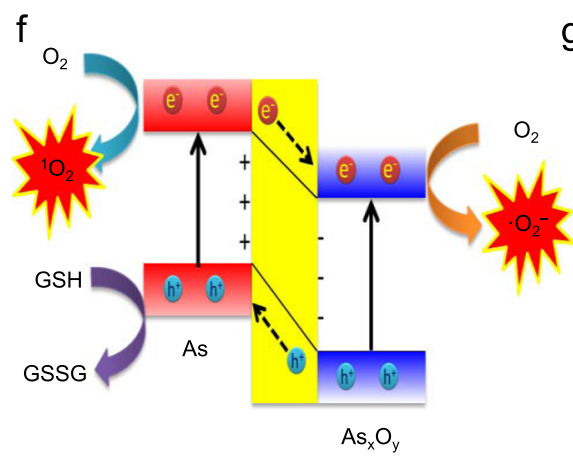

d

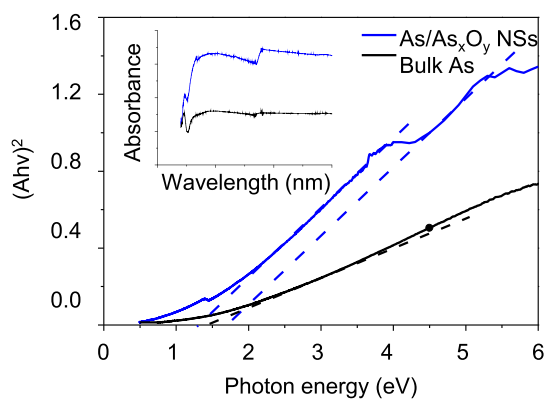

g

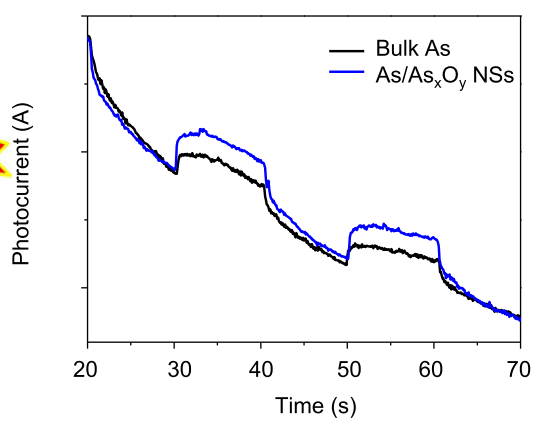

e

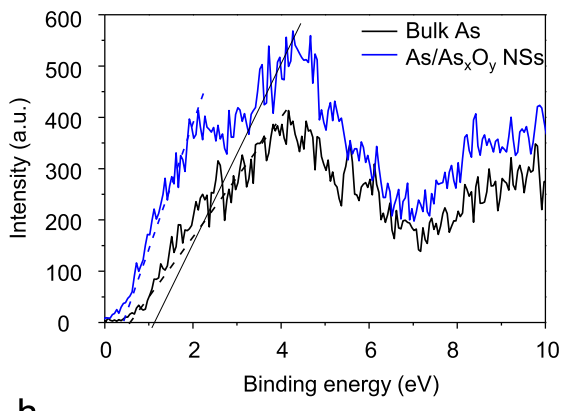

h

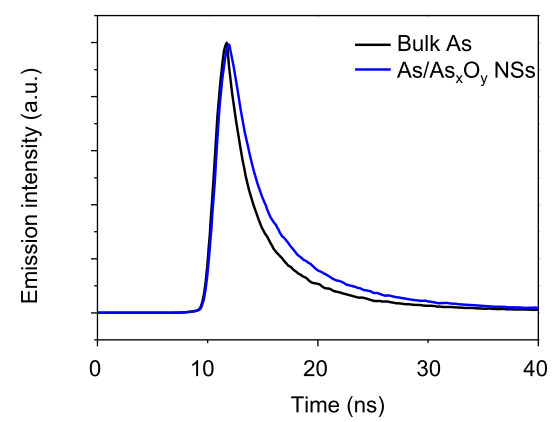

Fig. 5 Photocatalytic performance of $\mathbf{A s} / \mathbf{A s}_{\mathbf{x}} \mathbf{O}_{\mathbf{y}}$ NSs. The degradation of $\mathbf{a}$ DPBF and $\mathbf{b}$ GSH caused by $A s / \mathrm{As}_{x} \mathrm{O}_{y} \mathrm{NSs}$ under $660 \mathrm{~nm}$ laser irradiation at $0.3 \mathrm{~W} / \mathrm{cm}^{2}$. c ESR spectra of $\cdot \mathrm{O}_{2}{ }^{-}$and ${ }^{1} \mathrm{O}_{2}$ generated by As $/ \mathrm{As}_{x} \mathrm{O}_{y} \mathrm{NSs}$ under $660 \mathrm{~nm}$ laser irradiation at $0.3 \mathrm{~W} / \mathrm{cm}^{2}$. $\mathbf{d} \mathrm{UV}-\mathrm{Vis}$ absorbance spectra and calculated band gap of bulk As and $\mathrm{As} / \mathrm{As}_{x} \mathrm{O}_{y}$ NSs. e Valence band of bulk As and As/As $\mathrm{O}_{y}$ NSs calculated from XPS spectra. $\mathbf{f}$ Mechanism of type II heterojunction based on $\mathrm{As} / \mathrm{As}_{x} \mathrm{O}_{y} \mathrm{NSs}$ for $\cdot \mathrm{O}_{2}{ }^{-}$and ${ }^{1} \mathrm{O}_{2}$ generation and $\mathrm{GSH}$ oxidation. $\mathrm{g}$ Photocurrent curve of bulk $\mathrm{As}$ and $\mathrm{As} / \mathrm{As} \mathrm{O}_{y} \mathrm{NSs}$ under $660 \mathrm{~nm}$ laser irradiation. For the photocurrent analysis, three electrodes were used: glassy-carbon (working), silver-silver chloride (reference), and platinum (counter) electrodes in a sodium phosphate buffer $(100 \mathrm{mM}, \mathrm{pH} 7.0)$. h Time-resolved fluorescence spectra of $\mathrm{As}$ and $\mathrm{As} / \mathrm{As}_{x} \mathrm{O}_{y} \mathrm{NSs}$. Three times each experiment was repeated independently with similar results.

Fig. 5f. To be specific, when exposed to $660 \mathrm{~nm}$ laser, the As and $\mathrm{As}_{x} \mathrm{O}_{y}$ of $\mathrm{As} / \mathrm{As}_{x} \mathrm{O}_{y}$ NSs were simultaneously excited. The electrons in the $\mathrm{CB}$ of $\mathrm{As}$ in the developed type II As/ $\mathrm{As}_{x} \mathrm{O}_{y}$ NSs heterojunction preferably transfer to the $\mathrm{CB}$ of $A s_{x} \mathrm{O}_{y}$. In the meantime, the holes in the $\mathrm{VB}$ of $\mathrm{As}_{x} \mathrm{O}_{y}$ preferred to transfer to the $\mathrm{VB}$ of As, contributing to the thoroughly separate photoexcited charges into the $\mathrm{CB}$ and $\mathrm{VB}$ of two different photosensitizers, which fundamentally avoided electron-hole pair recombination. In addition, the $E^{0}$ of $\mathrm{O}_{2} / \cdot \mathrm{O}_{2}^{-}(-0.16 \mathrm{eV})$ and the $E^{0}$ of $\mathrm{GSH} / \mathrm{GSSG}(0.3 \mathrm{eV})$ were lower than that of the $\mathrm{CB}$ of $\mathrm{As}_{x} \mathrm{O}_{y}$ and the $\mathrm{VB}$ of As, respectively. Therefore, from a thermodynamic point of view, it became possible to transfer electrons from the $\mathrm{CB}$ of $\mathrm{As}_{x} \mathrm{O}_{y}$ to $\mathrm{O}_{2}$ for the generation of $\mathrm{O}_{2}{ }^{-}$ and capture of electrons by VB of As to produce GSSG from GSH. Moreover, the photochemical properties of the As $/ \mathrm{As}_{x} \mathrm{O}_{y}$ NSs-based type II heterojunction were further investigated. As 
shown in Fig. 5g, the photocurrent response versus time of As/ $\mathrm{As}_{x} \mathrm{O}_{y}$ NSs was higher than that of As NSs. The photocurrent response of $\mathrm{As} / \mathrm{As}_{x} \mathrm{O}_{y}$ NSs was reversible and stable under the increased current and was quenched reproducibly by on/off irradiation. The high photocurrent of $\mathrm{As} / \mathrm{As}_{x} \mathrm{O}_{y}$ NSs was responsible for the super-photocatalytic activity. This indicated that the electrons excited by $660 \mathrm{~nm}$ laser were transferred from the GSH to the electrode through the As/ $\mathrm{As}_{x} \mathrm{O}_{y} \mathrm{NSs}$. To confirm the suppressed recombination of electron-hole pairs in $A s / \mathrm{As}_{x} \mathrm{O}_{y}$ NSs, time-resolved fluorescence decay analysis was further performed. As shown in Fig. $5 \mathrm{~h}$, the $\mathrm{As} / \mathrm{As}_{x} \mathrm{O}_{y} \mathrm{NSs}$ possessed a longer fluorescence lifetime than As NSs, indicating that the incorporation of As and $\mathrm{As}_{x} \mathrm{O}_{y}$ with the formed type II heterojunction increased the photoelectron lifetime of $\mathrm{As} / \mathrm{As}_{x} \mathrm{O}_{y}$ NSs. This result further confirmed that $\mathrm{As} / \mathrm{As}_{x} \mathrm{O}_{y} \mathrm{NSs}$-based type II heterojunction provides a much more efficient light energy transfer and could also mediate a highly efficient ROS burst directly and indirectly.

Photothermal conversion and TME-responsive biodegradation. After confirming the excellent ability of As/As $\mathrm{O}_{y}$ NSs for mediating ROS burst in vitro, the biodegradability of $\mathrm{As} / \mathrm{As}_{x} \mathrm{O}_{y} \mathrm{NSs}$ and As/As $\mathrm{O}_{y} @ \mathrm{PDA}$ NSs dispersed in PBS and TME mimetic solution were examined. As presented in Fig. 6a, the $A s / \mathrm{As}_{x} \mathrm{O}_{y}$ NSs showed fast degradation in PBS solution, which is fatal for storage and blood circulation of nanoagents. After PDA coating, the As/As $\mathrm{O}_{y} @ P D A$ NSs demonstrated excellent stability under normal physiological conditions. Vis-NIR absorbance spectra of $\mathrm{As} / \mathrm{As}_{x} \mathrm{O}_{y} @ \mathrm{PDA} \mathrm{NSs}$ incubated in PBS indicated good stability (Fig. 6b), which bodes well for storage and blood circulation. The biodegradability of $\mathrm{As} / \mathrm{As}_{x} \mathrm{O}_{y} @ \mathrm{PDA} \mathrm{NSs}$ under simulated TME condition was further measured. As shown in Fig. 6c, TMEresponsive biodegradability was also observed.

The potential of NIR-induced hyperthermia of 2D nanomaterials is regarded as a promising cancer therapy strategy. To assess photothermal conversion performance, the $A s / \mathrm{As}_{x} \mathrm{O}_{y}$ NSs and As/As $x \mathrm{O}_{y} @ \mathrm{PDA}$ NSs at different concentrations (Supplementary Fig. 5) were exposed to an $808 \mathrm{~nm}$ laser $\left(2 \mathrm{~W} \mathrm{~cm}^{-2}\right)$. As presented in Fig. 6d, definite photothermal conversion ability of $\mathrm{As} / \mathrm{As}_{x} \mathrm{O}_{y}$ NSs was observed, with the greatest temperature change $\left(\Delta T_{\max }\right)$ of $14^{\circ} \mathrm{C}$ after laser irradiation $\left(5 \mathrm{~min}, 2 \mathrm{~W} \mathrm{~cm}^{-2}\right)$. Nevertheless, the photothermal conversion efficiency of $\mathrm{As} / \mathrm{As}_{x} \mathrm{O}_{y} \mathrm{NSs}$ was much lower than that of other recently reported $2 \mathrm{D}$ nanomaterials ${ }^{24,40,41}$. In addition, the $A s / A s_{x} \mathrm{O}_{y}$ NSs exhibited very poor photothermal stability (Fig. $6 \mathrm{~g}$ ), which may be because the high-temperature accelerated degradation. As reported previously, the PDA shell not only improved the stability of As/ $\mathrm{As}_{x} \mathrm{O}_{y}$ NSs in normal physiological environment, but also exhibited a robust photothermal conversion performance ${ }^{42}$. Hence, the As/As $\mathrm{O}_{y} @ P D A$ NSs possess excellent photothermal conversion efficiency, with the greatest temperature change $\left(\Delta T_{\max }\right)$ of $24^{\circ} \mathrm{C}$ after NIR laser irradiation $\left(5 \mathrm{~min}, 2 \mathrm{~W} \mathrm{~cm}^{-2}\right)$ (Fig. 6e). Moreover, the photothermal stability of As/ $\mathrm{As}_{x} \mathrm{O}_{y} @ \mathrm{PDA} \mathrm{NSs}$ was further examined by exposing the As/ $\mathrm{As}_{x} \mathrm{O}_{y} @ \mathrm{PDA} \mathrm{NSs}$ solution to the laser for five on/off irradiation cycles. As displayed in Fig. 6g, negligible changes in photothermal conversion ability were observed, clearly suggesting the high photothermal stability of $\mathrm{As} / \mathrm{As}_{x} \mathrm{O}_{y} @ \mathrm{PDA}$ NSs. Further, photothermal conversion performance of $\mathrm{As} / \mathrm{As}_{x} \mathrm{O}_{y} @ P D A$ NSs in a TME-mimicking solution was also assessed (Fig. 6f). The photothermal conversion ability of $\mathrm{As} / \mathrm{As}_{x} \mathrm{O}_{y} @ \mathrm{PDA} \mathrm{NSs}$ was observed similarly to that of in PBS solution for the first cycle, and a slight decrease of which was noticed after five cycles, which also demonstrated the TME-responsive biodegradability of As/ $\mathrm{As}_{x} \mathrm{O}_{y} @ \mathrm{PDA} \mathrm{NSs}$. As shown in Supplementary Fig. 6, the photothermal conversion ability of $\mathrm{As} / \mathrm{As}_{x} \mathrm{O}_{y} @ \mathrm{PDA} @ \mathrm{M}$ NSs was not changed after membrane coating.

Active cancer cell targeting and fluorescence imaging in vitro. Although nanoagents with size of 20-200 $\mathrm{nm}$ have the advantage of passive accumulation through the enhanced permeability and retention (EPR) effect in tumors, creating nanoagents with active targeting ability through cancer cell membrane engineering is still one of the most important goals of nanomedicine ${ }^{43}$. As shown in Fig. 7a, due to the narrow-band-gap of As NSs, As/As $\mathrm{O}_{y} @ \mathrm{PDA} @ \mathrm{M}$ Ns exhibited obvious photoluminescence (PL) property. It is well known that the PL signals of semiconductor materials result from the recombination of photo-induced charge carriers. As mentioned before, the photo-excited process of $\mathrm{As} / \mathrm{As}_{x} \mathrm{O}_{y} @ \mathrm{PDA} @ \mathrm{NSs}$ occurred upon laser irradiation, in which the electrons from the $\mathrm{VB}$ are promoted to the $\mathrm{CB}$ with simultaneous generation of holes in the VB. However, the excited electrons in the CB easily come back to the VB via a certain course to recombine with the holes. During the recombination process of photo-induced charge carriers, a certain amount of chemical energy can be released, which would further transform possibly to light energy. As exhibited in Fig. 7a, As NSs showed a relatively strong PL signal (excitation: $500 \mathrm{~nm}$; emission: $795 \mathrm{~nm}$ ), which also demonstrated serious recombination of photoinduced charge carriers. The decreased PL signal of As/As $\mathrm{O}_{y} @ \mathrm{P}-$ DA@M NSs further confirmed the retard recombination of photoinduced charge carriers through type II heterojunction. Additionally, although the type II heterojunction retarded the recombination to some extent, there were still a certain amount of photo-induced charge carriers recombined in $\mathrm{VB}$, which was the main reason for the $\mathrm{PL}$ phenomenon of $\mathrm{As} / \mathrm{As}_{x} \mathrm{O}_{y} @ \mathrm{PDA} @ \mathrm{M}$ NSs both in vitro and in vivo. To investigate the active targeting and accumulation ability of As/As $\mathrm{O}_{y} @ \mathrm{PDA} @ \mathrm{M}$ NSs in tumor cells, the cellular uptake efficiency on MCF-7 cells was measured. After $2 \mathrm{~h}$ incubation, as shown in the cell fluorescence images (Fig. 7b), cells treated with As $/ \mathrm{As}_{x} \mathrm{O}_{y} @ \mathrm{P}$ DA@M NSs presented a much higher fluorescence intensity in their cytoplasm compared with that of $A s / \mathrm{As}_{x} \mathrm{O}_{y}$ NSs-treated or As/ $\mathrm{As}_{x} \mathrm{O}_{y} @ \mathrm{PDA}$ NSs-treated cells. Quantitative analysis of red fluorescence intensity in cellular cytoplasm provided further evidence for the effective active targeting and accumulation ability of $\mathrm{As} / \mathrm{As}_{x} \mathrm{O}_{y} @ \mathrm{P}$ DA@M NSs in tumor cells (Fig. 7c).

ROS burst in vitro. Next, the properties of $A s / \mathrm{As}_{x} \mathrm{O}_{y} @ \mathrm{PDA} @ \mathrm{M}$ NSs for inducing ROS burst were investigated on a cellular level by employing 2,7-dichlorofluorescin diacetate (DCFH-DA) as the intracellular ROS detection probe, which could be oxidized by ROS to emit green fluorescence. As exhibited in Fig. $7 \mathrm{~d}-\mathrm{f}$ and Supplementary Fig. 7, cancer cells treated with $\mathrm{As} / \mathrm{As}_{x} \mathrm{O}_{y} @ \mathrm{P}$ DA@M NSs showed an obvious ROS production compared with that of the control group, which could be assigned to the following two causes. First, as mentioned earlier, the $\mathrm{As} / \mathrm{As}_{x} \mathrm{O}_{y} \mathrm{NSs}$ possessed a Fenton-like reactions-based catalyzed ability, which could disproportionately catalyze the reaction of $\mathrm{H}_{2} \mathrm{O}_{2}$ to generate $\cdot \mathrm{OH}$ and $\mathrm{O}_{2}$. Second, as previously reported, $\mathrm{As}_{2} \mathrm{O}_{3}$ has a high affinity to mercapto groups ${ }^{44}$, which could bind to antioxidants and anti-oxidases containing sulfhydryl groups in cells. Therefore, $\mathrm{As}_{2} \mathrm{O}_{3}$ would reduce cell clearance and antagonism to oxidation, breaking the dynamic balance of intracellular antioxidation, and contributing to increased intracellular ROS level. Moreover, the strongest green fluorescence signal was observed in cells treated with $\mathrm{As} / \mathrm{As}_{x} \mathrm{O}_{y} @ \mathrm{PDA} @ \mathrm{M}$ NSs plus $660 \mathrm{~nm}$ laser irradiation treatment. Additionally, a hypoxic probe was also employed to evaluate the TEM after different treatments. After treatment with $\mathrm{As} / \mathrm{As}_{x} \mathrm{O}_{y} @ \mathrm{PDA} @ \mathrm{M} \mathrm{NSs}$, a weak green fluorescence indicating the production of some $\mathrm{O}_{2}$ confirmed the $\mathrm{O}_{2}$ elevating ability of $\mathrm{As} / \mathrm{As}_{x} \mathrm{O}_{y} @ \mathrm{PDA} @ \mathrm{M}$ Ns via Fenton-like 
a

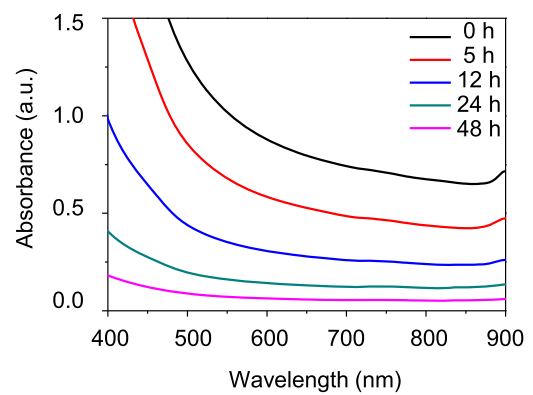

d

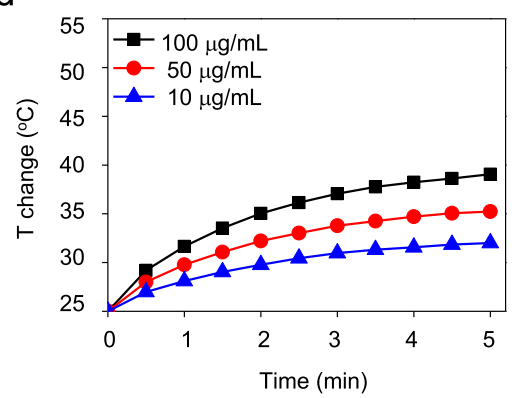

b

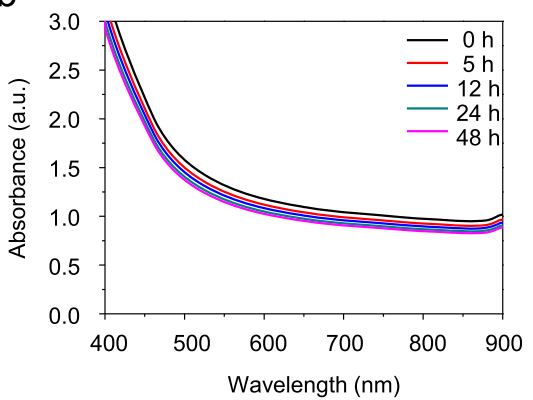

e

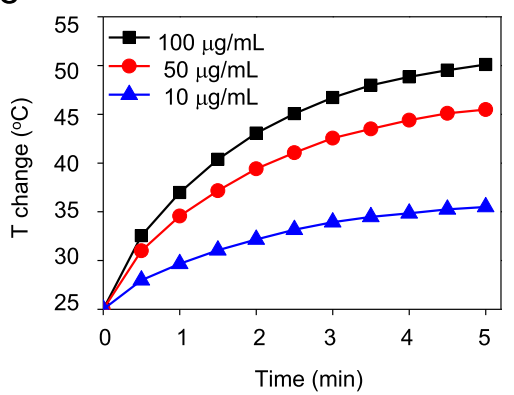

C

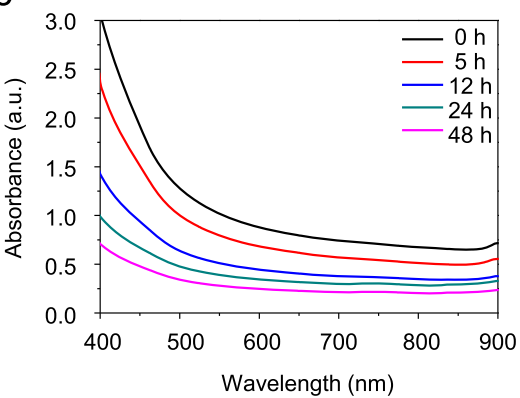

f

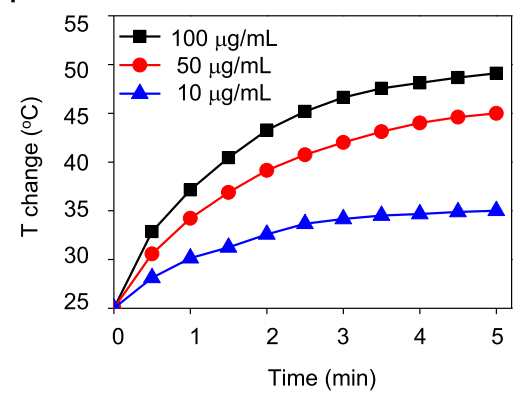

g

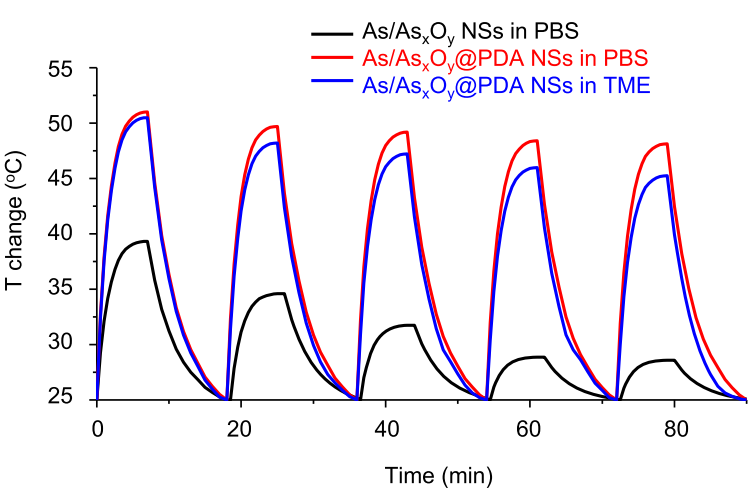

h

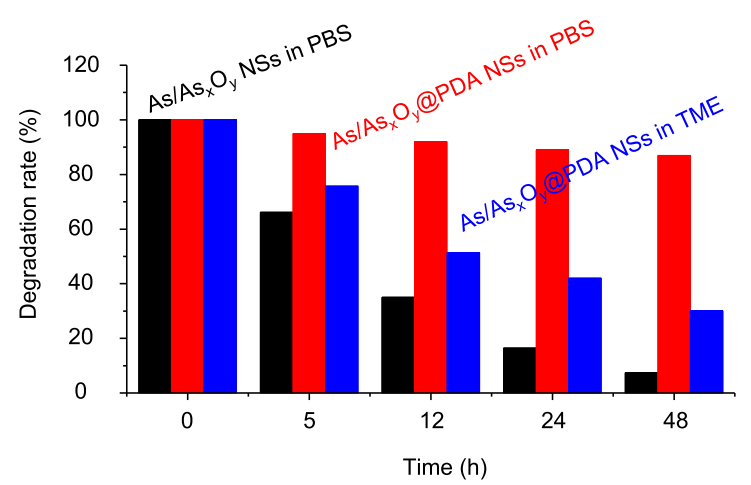

Fig. 6 Photothermal conversion and stability of As/As $\mathbf{A}_{\mathbf{y}} @$ PDA NSs. UV-Vis absorbance spectra of a $A s / A s_{x} \mathrm{O}_{y} N S s$ and $\mathbf{b}$ As/As $\mathrm{O}_{y} @ P D A N S s$ in PBS solution for different time intervals. c UV-Vis absorbance spectra of As/As $\mathrm{O}_{y} @ P D A$ NSs in TME-mimicking solution for different time periods. Photothermal conversion curves of $\mathbf{d} A s / \mathrm{As}_{x} \mathrm{O}_{y} \mathrm{NSs}$ and $\mathbf{e} \mathrm{As} / \mathrm{As}_{x} \mathrm{O}_{y} @ P D A$ NSs in PBS solutions. f Photothermal conversion curves of As/As $\mathrm{O}_{y} @ P D A$ NSs in TME-mimicking solution. $g$ Photothermal conversion stability of $A s / A s_{x} \mathrm{O}_{y}$ NSs and $A s / A s_{x} \mathrm{O}_{y} @ P D A$ NSs in PBS and in TME-mimicking solutions, respectively. $\mathbf{h}$ Degradation performance of $\mathrm{As} / \mathrm{As}_{x} \mathrm{O}_{y} \mathrm{NSs}$ and $\mathrm{As} / \mathrm{As}_{x} \mathrm{O}_{y} @ P D A$ NSs in PBS and TME-mimicking solutions, respectively. Three times each experiment was repeated independently with similar results.

reactions (Fig. $7 \mathrm{~g}$ and $\mathrm{h}$ ). As a result of the photodynamic effect of As/As $\mathrm{O}_{y} @ \mathrm{PDA} @ \mathrm{M}$ Ns, the concentration of $\mathrm{O}_{2}$ was decreased upon the $660 \mathrm{~nm}$ laser irradiation (Fig. $7 \mathrm{~g}$ and $\mathrm{h}$ ). It is well known that high ROS content will induce high levels of irreparable DNA damage in cancer cells. To visually observe the irreparable DNA damage levels in MCF-7 cells after different treatments, immunofluorescent staining assay was performed to detect the irreparable DNA damage in the nucleus using $\gamma-\mathrm{H} 2 \mathrm{AX}$ to stain DNA damage sites. As shown in Fig. 7i and Supplementary Fig. 8, the treatment of $\mathrm{As} / \mathrm{As}_{x} \mathrm{O}_{y} @ \mathrm{PDA} @ \mathrm{M}$ NSs induced obvious irreparable DNA damage in MCF-7 cells. Moreover, the treatment of $\mathrm{As} / \mathrm{As}_{x} \mathrm{O}_{y} @ \mathrm{PDA} @ \mathrm{M}$ NSs coupling with $660 \mathrm{~nm}$ laser irradiation induced remarkably high levels of irreparable DNA damage in cancer cells. These findings further confirmed the highly efficient photodynamic effect mediated by the type II heterojunction-based $\mathrm{As} / \mathrm{As}_{x} \mathrm{O}_{y} @ \mathrm{PDA} @ \mathrm{M}$ NSs to catalyze $\cdot \mathrm{O}_{2}{ }^{-}$and ${ }^{1} \mathrm{O}_{2}$ generation on the one hand, and to deplete GSH on the other hand, leading to the desired intracellular ROS burst (Fig. 7j).
Antitumor strategy in vitro. The phototherapy, especially PDT, has been clinically applied or under clinical trials to treat lung cancers and breast cancers ${ }^{45}$. For instance, during 1994-1998, Porfimer sodium, an organic photosensitizer, was granted regulatory approval for PDT towards non-small-cell lung cancer among serval countries (e.g., Japan, USA, Canada, Germany, and UK). Thereafter, some other photosensitizers (e.g., Talaporfin) were also approved for PDT of lung cancer. As for breast cancer, treatment of primary breast cancer using PDT has been carried out with results pending (e.g., ClinicalTrials.gov Identifier: NCT02872064). Moreover, although the therapeutic efficacy of light-assisted PDT and PTT might be hindered by the penetration depth of light, using a different light-delivery approach (e.g., light fiber) could be performed on lung and breast tumors. For instance, laser interstitial thermal therapy (LITT), generally involving placement of laser fibers into tumors, has been explored for the treatment of benign breast tumor (ClinicalTrials.gov Identifier: NCT00807924). Considering the clinical application of phototherapy for the treatment of lung and breast tumors, we, 

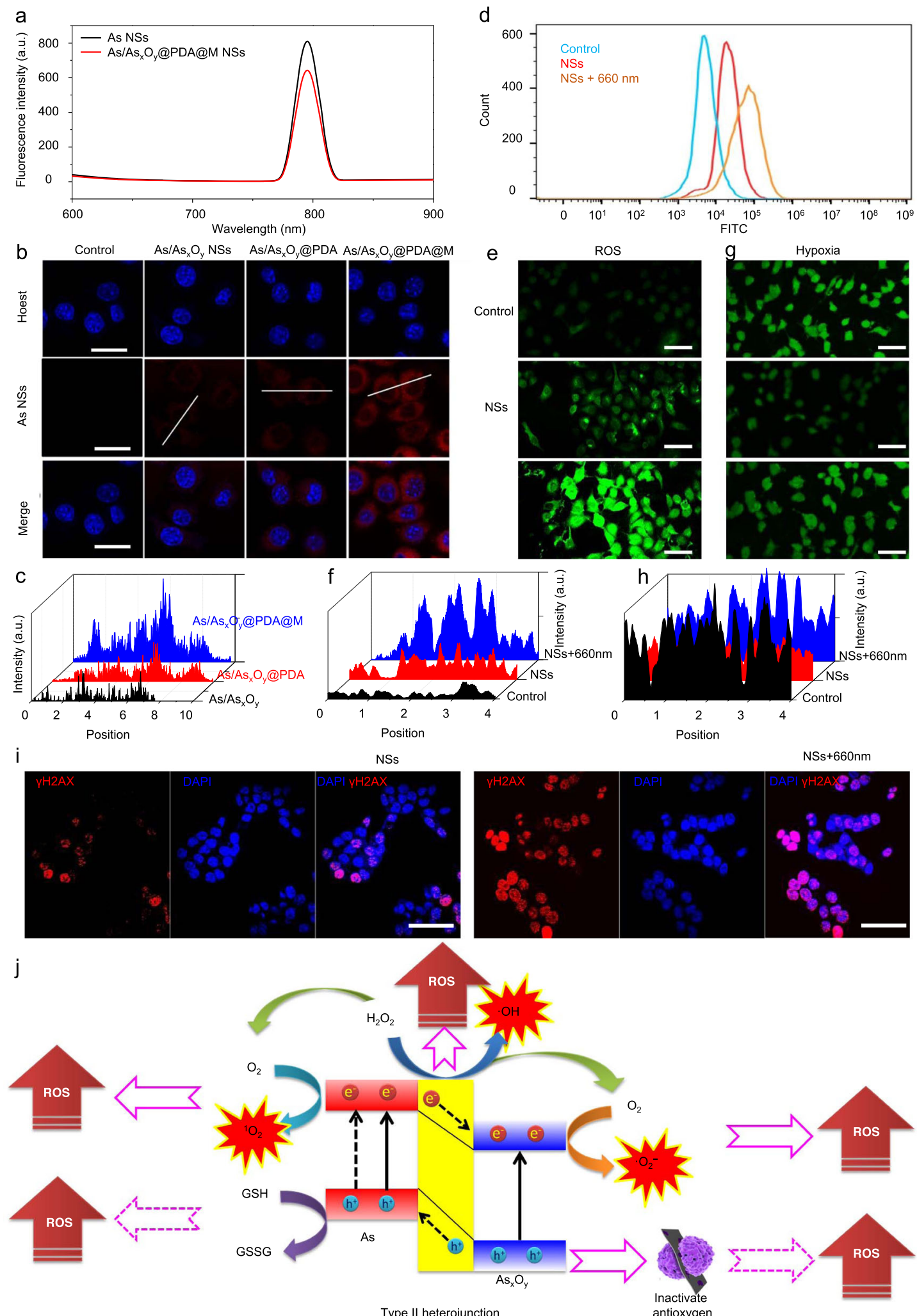

therefore, use A549 (lung cancer cells) and MCF-7 (breast cancer cells) cell lines to demonstrate the practicality of our developed As/As $\mathrm{O}_{y} @ \mathrm{PDA} @ \mathrm{M}$ NSs.

Next, the cytotoxicity of prepared As/As $\mathrm{O}_{y} @ P D A @ M ~ N S s$ on two human cancer cell lines (A549 and MCF-7) and two human normal cell lines (HL-7702 liver cells and HEK293 embryonic kidney cells) were evaluated. As/As $\mathrm{O}_{y} @ \mathrm{PDA} @ \mathrm{M}$ NSs clearly showed significant cell inhibition ability on the two cancer cell lines with an inhibition percentage of $50 \%$ at a concentration of $10 \mu \mathrm{g} / \mathrm{mL}$; by contrast, only $20 \%$ cell inhibition was detected in the two human normal cell lines, indicating significant selective killing effect of As/As $\mathrm{O}_{\mathrm{y}} @ \mathrm{PDA} @ \mathrm{M}$ NSs (Fig. 8a). As mentioned before, As $/ \mathrm{As}_{x} \mathrm{O}_{y}$ NSs could catalyze Fenton-like reactions and bind to anti-oxidants and anti-oxidases containing sulfhydryl 
Fig. 7 Intracellular uptake and ROS generation. a Fluorescence spectrum of As NSs and As/As $\mathrm{O}_{y} @ P D A @ M ~ N S s$ with the excitation wavelength at 500 $\mathrm{nm}$ and emission wavelength at $795 \mathrm{~nm}$. b Intracellular uptake of NSs in various formations after incubation for $4 \mathrm{~h}$ characterized by LSCM with the excitation wavelength at $500 \mathrm{~nm}$ and emission wavelength at $795 \mathrm{~nm}$. Scale bars $=50 \mu \mathrm{m}$. c Fluorescence quantitative analysis of the intracellular uptake of NSs. $\mathbf{d}$ Intracellular ROS generation detected by FCM. e and $\mathbf{g}$ Intracellular ROS and $\mathrm{O}_{2}$ generation detected by CLSM. Scale bars $=100 \mu \mathrm{m}$. $\mathbf{f}$ and h Fluorescence quantitative analysis of intracellular ROS and $\mathrm{O}_{2}$ generation. i Representative confocal microscopy images of the MCF-7 cells (scale bars, $50 \mu \mathrm{m}$ ) after different treatments. The nuclei were stained by DAPI (blue), and the $\gamma \mathrm{H} 2 \mathrm{AX}$ foci per nucleus were stained by anti- $\gamma \mathrm{H} 2 \mathrm{AX}$ antibody (red). j Mechanism of As/As $\mathrm{O}_{y} @ P D A @ M ~ N S s$ for modulating ROS burst. The engineered As/As $\mathrm{O}_{y} @ P D A @ M$ NSs serve as an intelligent theranostic platformmediated ROS burst through five pathways. For the intracellular uptake, ROS and $\mathrm{O}_{2}$ generation, and DNA damage of developed NSs, three times each experiment was repeated independently with similar results.

groups, leading to the reduced ability of cell clearance and antagonism to oxidation to increase the intracellular ROS concentration. This might be the main reason for the significant selective cytotoxicity of As/As $\mathrm{O}_{y} @ \mathrm{PDA} @ \mathrm{M}$ Ns. As shown in Fig. 8 b and Supplementary Fig. 9, although there was a degree of cell death after treatment with As/As $\mathrm{O}_{y} @ \mathrm{PDA} @ \mathrm{M}$ NSs plus 808 $\mathrm{nm}$ laser irradiation (PTT), dose-dependent severe cell death was observed when cells were treated with As/As $\mathrm{O}_{y} @ \mathrm{PDA} @ \mathrm{M}$ NSs plus $660 \mathrm{~nm}$ light irradiation (PDT), which indicated that the ROS burst was the main cause for serious cell death. In addition, the As/As $\mathrm{O}_{y} @ P D A @ M ~ N S s-t r e a t e d ~ c e l l s ~ u p o n 660$ and 808 nm laser irradiation showed significantly reduced viability, demonstrating the highly enhanced therapeutic effect by the ROS burst and PTT. To explore the mechanisms underlying these therapeutic outcomes, an apoptotic study was carried out. As detected by flow cytometry (Fig. 8c and Supplementary Fig. 10), early and late apoptotic cells with a percentage of $15.5 \%$ and $16.4 \%$, respectively, were observed. As one of the earliest phenomena in cell apoptosis, a change in mitochondrial transmembrane potential was observed, confirming that apoptosis began after As/As $\mathrm{O}_{y} @ \mathrm{PDA} @ \mathrm{M}$ NSs treatment. JC- 1 dye $\left(5,5^{\prime}, 6,6^{\prime}\right.$-tetrachloro-1, $1^{\prime}, 3,3^{\prime}$-tetraethylbenzimidazolcarbocyanine iodide) was used to measure mitochondrial membrane potential (MMP) change. As presented in Fig. 8d, the depolarization of the mitochondria (an early apoptosis signal) was observed, further confirming the apoptosis of cancer cells induced by As/ $\mathrm{As}_{x} \mathrm{O}_{y} @ \mathrm{PDA} @ \mathrm{M}$ NSs. Moreover, as confirmed previously, the prepared type II heterojunction-functionalized As/As $\mathrm{O}_{y} @ \mathrm{P}$ DA@M NSs possess robust ability to generate $\mathrm{ROS}$ (e.g., $\cdot \mathrm{O}_{2}{ }^{-}$ and ${ }^{1} \mathrm{O}_{2}$ ) and consume $\mathrm{GSH}$ under $660 \mathrm{~nm}$ laser irradiation, which would mediate a drastic ROS burst in cells to induce apoptosis of cancer cells. The numbers of dead and live cells in the different treatment groups further supported the effective therapeutic effect of As/As $\mathrm{O}_{y} @ \mathrm{PDA} @ \mathrm{M}$ NSs (Fig. 8e).

Fluorescence imaging and antitumor strategy in vivo. Encouraged by the excellent in vitro ROS burst ability, selective killing effect, as well as TEM-responsive degradation, the in vivo therapeutic outcomes of As/As $\mathrm{O}_{y} @ \mathrm{PDA} @ \mathrm{M}$ Ns were further investigated (Fig. 9a). To start with, owing to their intrinsic fluorescence properties, the in vivo fluorescence imaging ability of $\mathrm{As} / \mathrm{As}_{x} \mathrm{O}_{y} @ \mathrm{PDA} @ \mathrm{M}$ NSs were performed on the MCF-7 xenograft tumor model (via intravenous injection) to evaluate the biodistribution and tumor accumulation ability. As shown in Fig. 9b, the As/As $\mathrm{O}_{y} @ P D A @ M ~ N S s$ effectively and continuously accumulated at the tumor site. At $24 \mathrm{~h}$ post injection, the mice were sacrificed and the tumors were dissected. As exhibited in Fig. 9b, the tumor showed bright fluorescence signal, which was consistent with the in vivo biodistribution results. Additionally, pharmacokinetics analysis (Supplementary Fig. 11) demonstrated the long circulation time of $\mathrm{As} / \mathrm{As}_{x} \mathrm{O}_{y} @ \mathrm{PDA} @ \mathrm{M}$ NSs. Although the As/As $\mathrm{O}_{y} @ \mathrm{PDA} @ \mathrm{M}$ Ns also accumulated in some organs, such as the liver, spleen, and lung, their relatively good biocompatibility and low dosage guarantee negligible damage to these organs.

Bearing an excellent tumor accumulation ability, the in vivo therapeutic studies of As/As $\mathrm{O}_{y} @ \mathrm{PDA} @ \mathrm{M}$ NSs were carried out. MCF-7 tumor-bearing mice were randomly separated into six groups and received different treatments: Group 1: saline; Group 2: 660 nm+808 nm lasers; Group 3: As/As $\mathrm{O}_{y} @ \mathrm{PDA} @ \mathrm{MSs}$ Group 4: As/As $\mathrm{x}_{\mathrm{y}} @ \mathrm{PDA} @ \mathrm{M}$ Ns +808 nm laser; Group 5: As/ $\mathrm{As}_{\mathrm{x}} \mathrm{O}_{\mathrm{y}} @ \mathrm{PDA} @ \mathrm{M}$ NSs+660 nm laser; and Group 6: As/ $\mathrm{As}_{\mathrm{x}} \mathrm{O}_{\mathrm{y}} @ \mathrm{PDA} @ \mathrm{M}$ Ns $+660 \mathrm{~nm}+808 \mathrm{~nm}$ lasers. As/ $\mathrm{As}_{\mathrm{x}} \mathrm{O}_{\mathrm{y}} @ \mathrm{P}-$ DA@M NSs ( $3 \mathrm{mg} \mathrm{kg}^{-1}$ ) were intravenously injected into mice in Groups 3-6. Both laser treatments $\left(660 \mathrm{~nm}\right.$ at $0.3 \mathrm{~W} \mathrm{~cm}^{-2}$ for 10 min and $808 \mathrm{~nm}$ at $1.0 \mathrm{~W} \mathrm{~cm}^{-2}$ for $10 \mathrm{~min}$ ) were carried out at $24 \mathrm{~h}$ post injection of $\mathrm{As} / \mathrm{As}_{x} \mathrm{O}_{y} @ \mathrm{PDA} @ \mathrm{M}$ Ns. As revealed in Supplementary Figs. 12 and 13, significant temperature increases were observed in mice received As/ $\mathrm{As}_{x} \mathrm{O}_{y} @ \mathrm{PDA} @ \mathrm{M} \mathrm{NSs}+808$ nm laser (Group 4) or As/As $\mathrm{O}_{y} @ P D A @ M ~ N S s+660$ nm + 808 nm lasers (Group 6); by contrast no obvious changes were observed in mice that received only laser treatment, indicating the high photothermal conversion ability of $\mathrm{As} / \mathrm{As}_{x} \mathrm{O}_{y} @ \mathrm{PDA} @ \mathrm{M} \mathrm{NSs}$ in vivo. Then a course of therapeutic treatment was carried out. No significant inhibition of tumor growth was observed in the control (Group 1) or laser-only (Group 2) groups, but obvious inhibition of tumor growth was observed in As/As $x \mathrm{O}_{y} @ \mathrm{PDA} @ \mathrm{M}$ NSs-treated mice (Group 3). We attributed this to the accumulation of ROS through mediating Fenton-like reaction and inactivating some main anti-oxidants and anti-oxidases containing sulfhydryl groups to induce cancer cell apoptosis. Better therapeutic effects were observed in Group 4 (PTT) compared to Group 2, indicating the advantages of As/ $\mathrm{As}_{x} \mathrm{O}_{y} @ \mathrm{PDA} @ \mathrm{M}$ Ns as photothermal agents. Notably, a high level of inhibited tumor growth was observed in Group 5 because of the As/As $\mathrm{O}_{y} @ \mathrm{PDA} @ \mathrm{M}$-based nanomedicine with multiple independently targeted ROS burst. After 4 days, portions of the tumors recrudesced but exhibited a relatively slow growth rate compared with that of the control group. The highly effective therapeutic effect of the combined As/ $\mathrm{As}_{x} \mathrm{O}_{y} @ \mathrm{PDA} @ \mathrm{M}$ NSs and $660 \mathrm{~nm}$ laser irradiation was attributed to the dramatic ROS burst achieved via tripartite ROS generation and the blocked two main ROS consumption pathways. Of note, nearly complete elimination of tumors without recurrence was achieved in mice treated with As/As $\mathrm{O}_{y} @ \mathrm{PDA} @ \mathrm{M}$ NSs and 660 or 808 nm laser irradiation (Group 6), indicating the remarkably enhanced therapeutic effect of combined PTT and ROS burst. The weight of excised tumors from euthanized mice (Fig. 9e) showed further evidence for the excellent therapeutic outcomes of PTT combined with ROS burst. Correspondingly, As/ $\mathrm{As}_{x} \mathrm{O}_{y} @ \mathrm{PDA} @ \mathrm{M}$ coupled with 660 and $808 \mathrm{~nm}$ laser treatment was associated with a high survival rate (Fig. 9f). More importantly, no notable side effects were observed in the above treatment groups (Fig. 9g).

The ROS burst effect was also studied by staining with a DCFH-DA. The results in Fig. 9h show a slight ROS accumulation after treatment with $\mathrm{As} / \mathrm{As}_{x} \mathrm{O}_{y} @ \mathrm{PDA} @ \mathrm{M}$ Ns, which was 
a

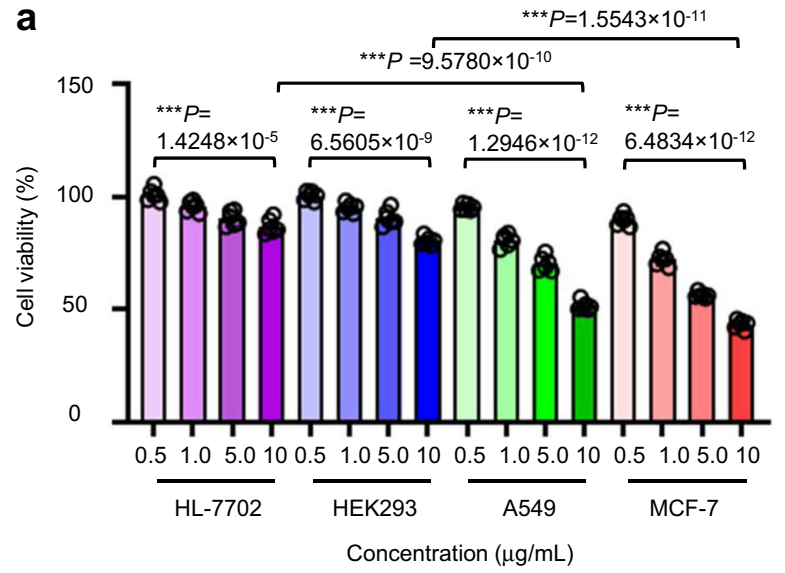

b

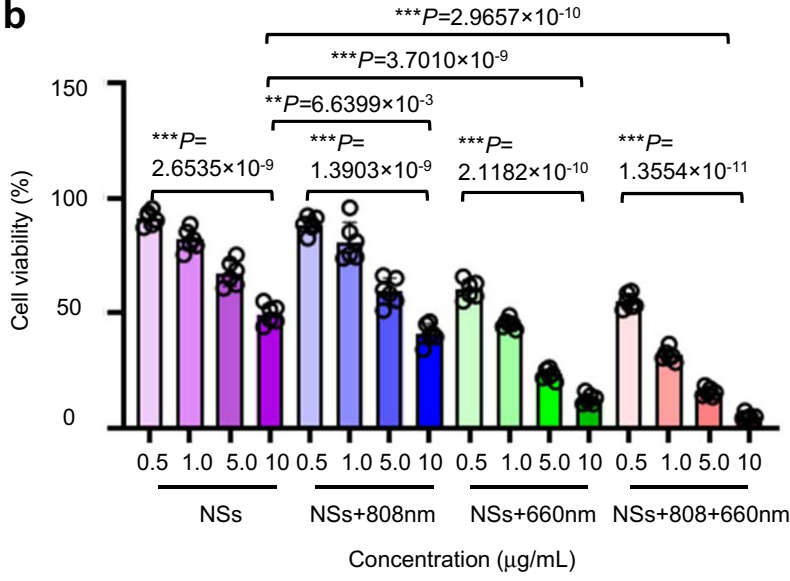

C
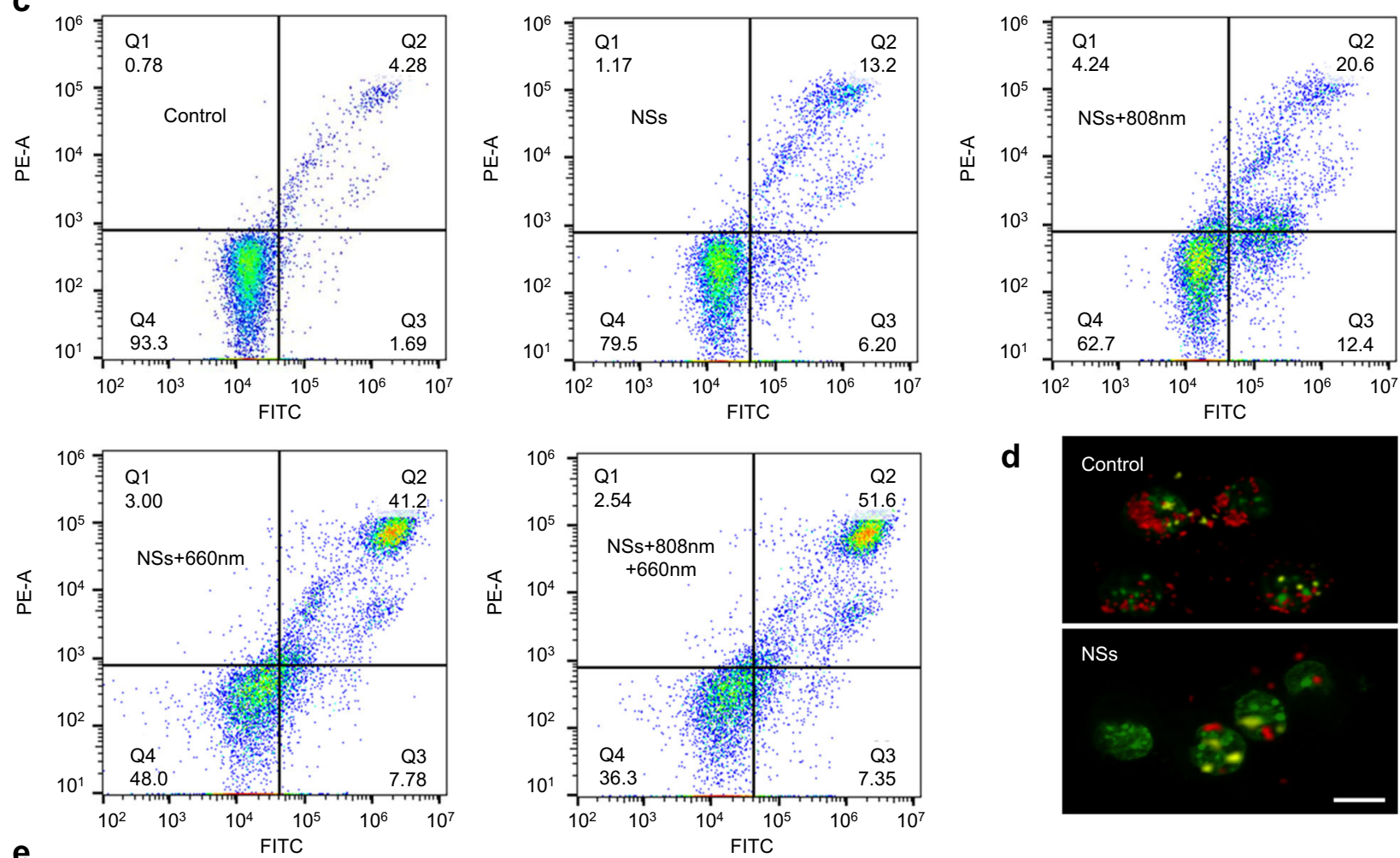

d
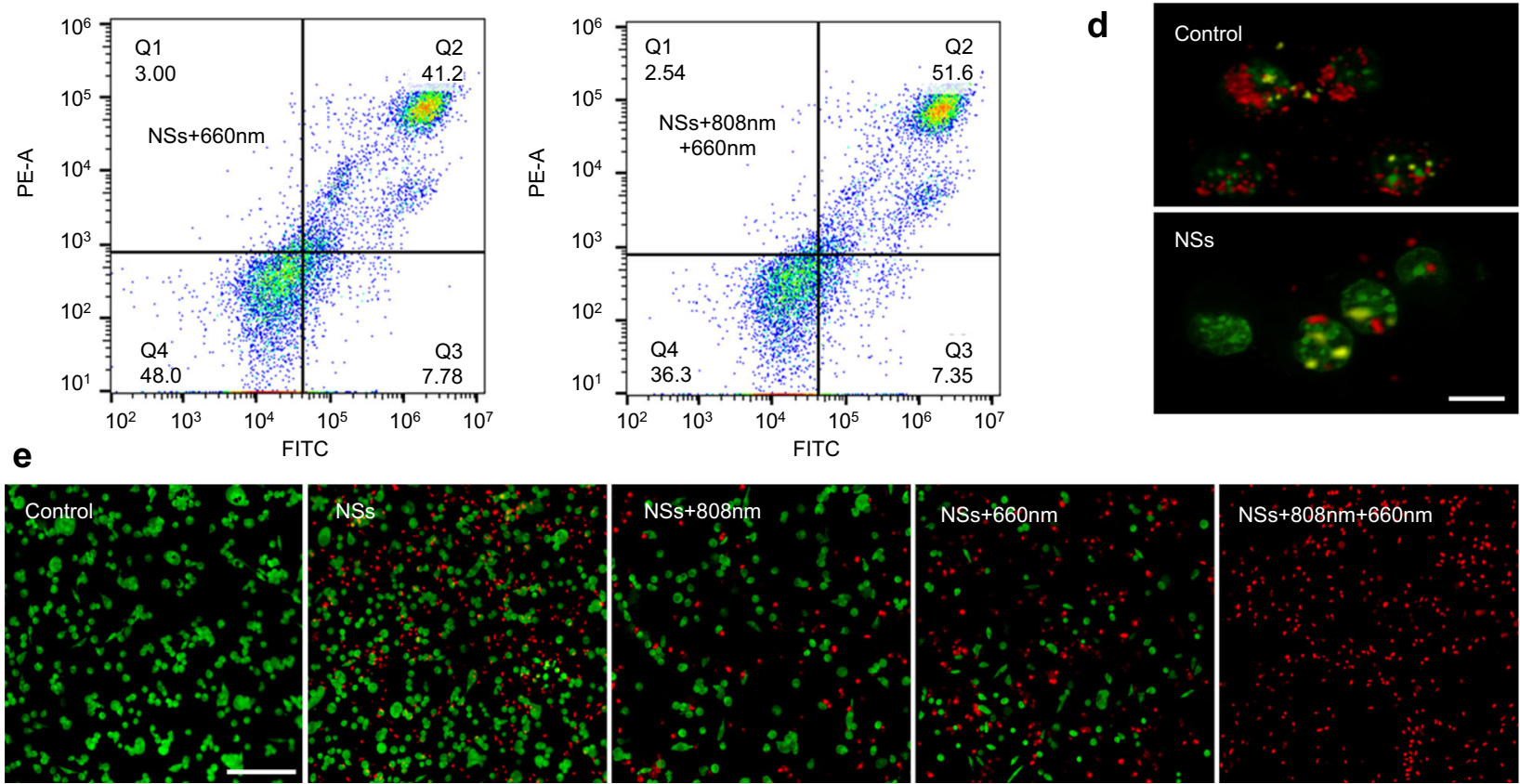

Fig. 8 Biocompatibility and cytotoxicity of As/Asx Oy@PDA@M NSs. a Relative viability of HL-7702, HEK293, A549, and MCF-7 cells after incubation with $\mathrm{As} / \mathrm{As}_{x} \mathrm{O}_{y} \mathrm{NSs}$ for $24 \mathrm{~h}$. b Relative viability of MCF-7 cells after incubation with As/As $\mathrm{O}_{y} @ P D A @ M$ NSs under different treatments for $24 \mathrm{~h}$. The power of $660 \mathrm{~nm}$ laser and $808 \mathrm{~nm}$ laser were 0.3 and $1.0 \mathrm{~W} \mathrm{~cm}^{-2}$, respectively. The exposure time was 10 min. Error bars $=$ standard deviation $(n=6)$, $n=6$ biologically independent cells. Data are presented as mean values \pm SEM. Two-sided ANOVAs were performed for all other comparisons. No adjustments were made for multiple comparisons. c FCM images of MCF-7 cells after incubation with As/As $\mathrm{O}_{y} @ P D A @ M$ NSs under different treatments for $12 \mathrm{~h}$. d Fluorescence microscopy images of mitochondrial membrane potential change detected by JC-1 staining (Red: hyperpolarization; Green: depolarization) (scale bars $=10 \mu \mathrm{m}$ ). e Florescent images of MCF-7 cells stained with calcein AM (Green: live cells) and PI (Red: dead cells) (scale bars = $200 \mu \mathrm{m}$ ). For the mitochondrial membrane potential change and live/dead cells staining, three times each experiment was repeated independently with similar results. 

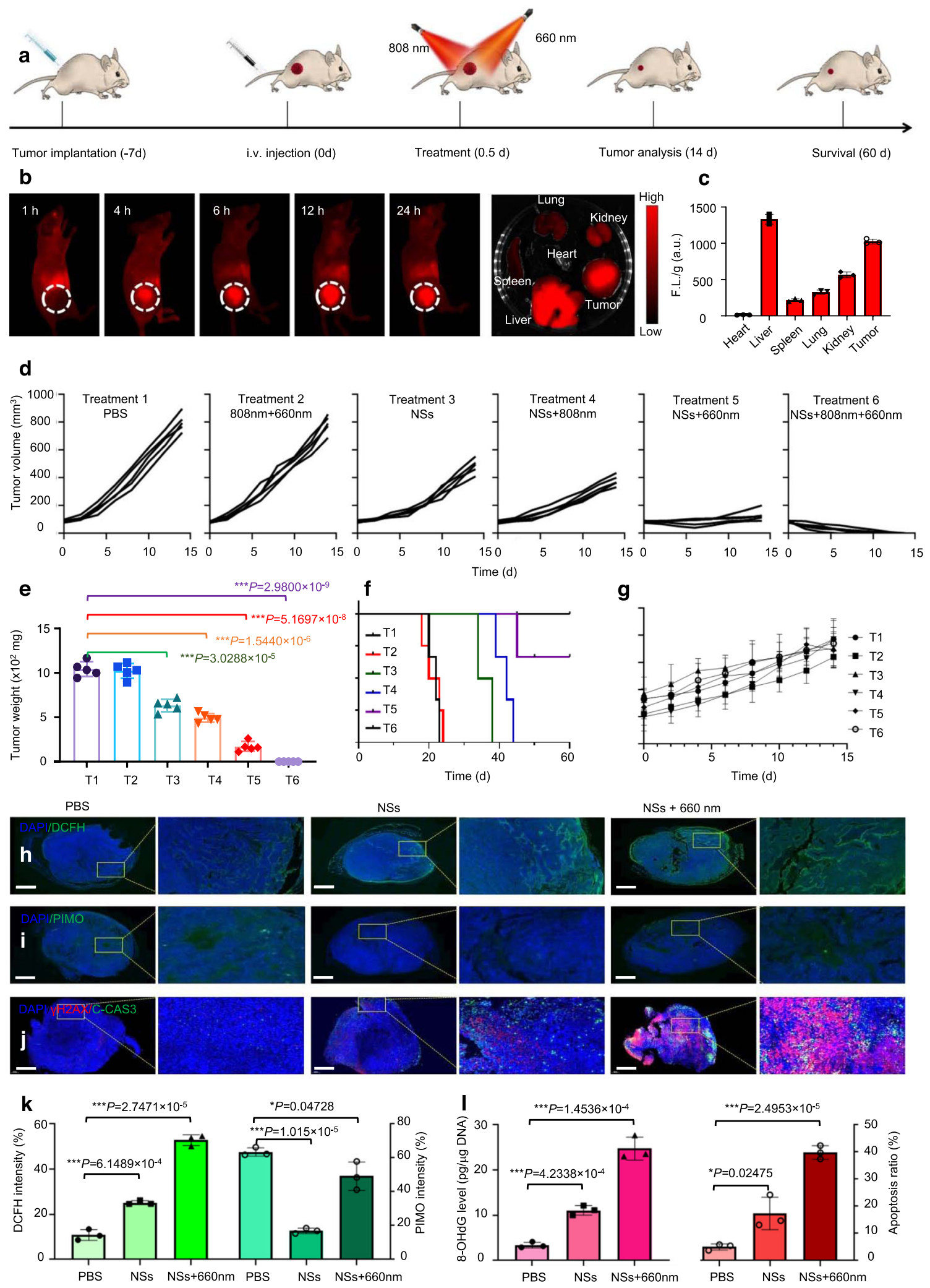

ascribed to mediation of a Fenton-like reaction and inactivation of some main anti-oxidants and anti-oxidases. Moreover, strong green fluorescence was detected in the As/As $\mathrm{O}_{y} @ \mathrm{PDA} @ \mathrm{M}$ NSs $+660 \mathrm{~nm}$ laser group, further indicating a drastic ROS burst in tumor cells. The Fenton-like reaction ability of $\mathrm{As} / \mathrm{As}_{x} \mathrm{O}_{y} @ \mathrm{P}$ DA@M NSs, such as the generation of $\mathrm{O}_{2}$, was also confirmed by the remission of hypoxic microenvironment exhibited in Fig. 9i. As previously reported ${ }^{46}$, the reason for ROS-induced cell toxicity is mainly DNA damage caused by ROS. We thus further assessed DNA damage levels and cell apoptosis in tumors after different treatment using $\gamma-\mathrm{H} 2 \mathrm{AX}$ and C-CAS3 as markers for DNA double-strand breaks and cell apoptosis, respectively ${ }^{47}$. 
Fig. 9 In vivo imaging and anti-tumor performance of As/As $\mathbf{O}_{\mathbf{y}} @$ PDA@M NSs. a Treatment schedule. $\mathbf{b}$ In vivo fluorescence images of nude mice after i.v. administration of NSs, and the ex vivo fluorescence images of the tumor and major organs at $24 \mathrm{~h}$ post-injection of As/As $\mathrm{O}_{y} @ P D A @ M ~ N S s$ with the

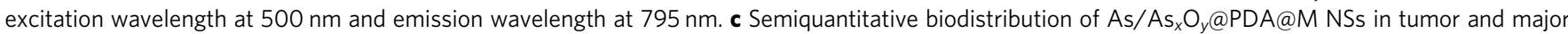
organs $24 \mathrm{~h}$ post-injection. Error bars = standard deviation $(n=3), n=3$ biologically independent samples. d Tumor growth curves of MCF-7 tumorbearing nude mice. e Tumor weight in different groups after 14 days of treatment. Error bars = standard deviation $(n=5), n=5$ biologically independent mice. $\mathbf{f}$ Survival rate of mice undergoing different treatments. $\mathbf{g}$ Body weight of mice during treatment. Error bars $=\operatorname{standard~deviation}(n=5), n=5$ biologically independent mice. $\mathbf{h}$ In vivo ROS detection in the sections from tumors by dichlorodihydrofluorescein (DCFH) via fluorescence microscopy, scale bars $=1000 \mu \mathrm{m}$. i In vivo $\mathrm{O}_{2}$ generation in sections from tumors by pimonidazole (PIMO) via fluorescence microscopy, scale bars $=1000 \mu \mathrm{m}$. j Immunofluorescence (IF) staining in tumor sections after treatment with PBS, NSs, or NSs $+660 \mathrm{~nm}$ laser irradiation, scale bars $=1000 \mu \mathrm{m}$. The nucleus is stained by DAPI (blue), damaged DNA by $\gamma \mathrm{H} 2 \mathrm{AX}$ foci (red), and apoptotic cells by apoptosis marker C-CAS3 (green). $\mathbf{k}$ Quantification of the in vivo ROS and $\mathrm{O}_{2}$ signals from the tumors calculated from the section studies in $\mathbf{h}$ and $\mathbf{i}$. I In vivo DNA damage of tumors measured by 8-OHdG assay and apoptosis ratio after different treatments. Error bars = standard deviation $(n=3), n=3$ biologically independent samples. For all statistical analysis, data are presented as mean values \pm SEM. Two-sided ANOVAs were performed for all other comparisons. No adjustments were made for multiple comparisons. For the in vivo fluorescence images and tumor IF staining, three times each experiment was repeated independently with similar results.

Treatment with As/As $\mathrm{O}_{y} @ \mathrm{PDA} @ \mathrm{M}$ NSs alone induced a certain extent of irreparable DNA damage and cancer cell apoptosis. When $660 \mathrm{~nm}$ laser irradiation was added, remarkably high levels of irreparable DNA damage and cell apoptosis in tumor section were observed (Fig. 9j). To further demonstrate this potential mechanism, 8-hydroxy-2'-deoxyguanosine (8-OHdG)-a reliable marker for oxidative stress-was detected after different treatments (Fig. 9k). As displayed in Fig. 9l, the 8-OHdG results showed trends consistent with the $\gamma$-H2AX data. Collectively, these results further confirmed that the therapeutic strategy based on As/As $\mathrm{O}_{y} @ \mathrm{PDA} @ \mathrm{M}$ NSs could efficiently induce a ROS burst and specifically kill effect on cancer cells.

Biocompatibility evaluation. Considering that the in vivo toxicity of the materials plays an important role in the translation from bench to practical applications, we further set forth to evaluate the toxicity of $\mathrm{As} / \mathrm{As}_{x} \mathrm{O}_{y} @ \mathrm{PDA} @ \mathrm{M}$ Ns. We assessed DNA damage levels through $\gamma$-H2AX staining, apoptosis levels through cleaved caspase-3 (C-CAS3) staining, and performed histological analyses through H\&E staining in vivo. As shown in Fig. 10a, no DNA damage, apoptosis, or signs of organ injury were detected in normal tissues, confirming the excellent in vivo biocompatibility of the As/ $\mathrm{As}_{x} \mathrm{O}_{y} @ \mathrm{PDA} @ \mathrm{M}$ NSs. Further, Masson staining of pathological fibrous deposition in main organs (kidney, heart, and liver) from mice treated with PBS, As/As $\mathrm{O}_{y} @ \mathrm{PDA} @ \mathrm{M}$ Ns, or As/ $\mathrm{As}_{x} \mathrm{O}_{y} @ \mathrm{PDA} @ \mathrm{M} \mathrm{Ns}+660 \mathrm{~nm}$ laser irradiation were performed. Sections from mice treated with NSs (with or without $660 \mathrm{~nm}$ laser irradiation) showed normal structures and no greater collagen deposition (blue staining) than sections from the PBS control group (Fig. 10b). Hence, these results clearly demonstrated that this therapeutic strategy based on As/As $\mathrm{O}_{y} @ \mathrm{PDA} @ \mathrm{M}$ NSs specifically targets tumor tissues in vivo while maintaining biocompatibility within normal tissues. Moreover, hematology assay, histology examination, and immune analysis further demonstrate biocompatibility. For the hematology and histology assay, blood examination was conducted at 1, 7, and 14 days post i.v. injection of As/As $\mathrm{O}_{y} @ \mathrm{PDA} @ \mathrm{M}$ Ns. As shown in Fig. 10c, no statistically significant differences in the amount of creatinine, aspartate aminotransferase (AST), albumin, total protein (TP), alanine aminotransferase (ALT), or blood urea nitrogen (BUN) were detected in mice that received As $/ \mathrm{As}_{x} \mathrm{O}_{y} @ \mathrm{PDA} @ \mathrm{M}$ NSs compared with that of control mice. For immune toxicity analysis, the amount of IFN- $\gamma$, IL-6, and TNF- $\alpha$ in serum samples from mice at 2 and 24 h post i.v. injection of $\mathrm{As} / \mathrm{As}_{x} \mathrm{O}_{y} @ \mathrm{PDA} @ \mathrm{M}$ NSs were measured. Figure 10d shows that all cytokine levels were nearly the same as those in the control group, further confirming that the obtained As $/ \mathrm{As}_{x} \mathrm{O}_{y} @ \mathrm{P}$ DA@M NSs are biocompatible in vivo.

\section{Discussions}

During past years, ultrathin two-dimensional (2D) nanomaterials have received a great deal of attention for both fundamental studies and practical applications owing to their unique properties such as large surface-to-volume ratio, high charge-carrier mobility, tunable direct-bandgap, mechanical flexibility, etc. Among the 2D nanomaterials family, 2D monoelemental nanosheets (Xenes), such as graphene, BP, antimonene, borophene, arsenene, etc., have emerged as an unique family of nanomaterials that show numerous advantages and superior performances in biomedicine as a result of their unique physicochemical features ${ }^{15,17-20,22}$. Compared with other multielemental nanosheets (transition metal dichalcogenides, MXenes, etc.), Xenes with a simple elemental composition decrease the materials toxicity in biological system. The atomic-scale thickness makes Xenes invaluable for drug/gene delivery and stimuliresponsive systems that require extensive surface interactions on a small scale. The excellent optical and electrical properties enable Xenes as potential biological fluorescence and/or photoacoustic imaging agents for cancer diagnosis, and optical therapy platforms. For example, graphene, BP, antimonene, and borophene have been successfully used as photothermal agents and drug/gene delivery carriers for cancer PTT and chemo/gene therapy ${ }^{18-20,22}$. In addition, BP with semiconductor optical properties has been applied as an efficient photosensitizer for cancer PDT ${ }^{48,49}$. Arsenene, especially the as-fabricated $\mathrm{As} / \mathrm{As}_{x} \mathrm{O}_{y} \mathrm{NSs}$ in this study, exhibit excellent totipotency and pluripotency compared to the other Xenes. Firstly, $\mathrm{As} / \mathrm{As}_{x} \mathrm{O}_{y}$ NSs with large surface-to-volume ratio and high photothermal conversion efficiency could be applied as drug/gene delivery carriers and photothermal agents for cancer chemo/gene therapy and PTT. Secondly, As/As $\mathrm{O}_{y}$ NSs as type II heterojunction showed efficient $\mathrm{ROS}\left({ }^{1} \mathrm{O}_{2}\right.$ and $\left.\cdot \mathrm{O}_{2}{ }^{-}\right)$generation and $\mathrm{GSH}$ consumption, which mediated intracellular ROS burst and apoptosis of cancer cells. Thirdly, different from other Xenes, As/As $x \mathrm{O}_{y}$ NSs also possess ability to modulate TME and catalyze Fenton-like reaction to provide substrates of $\mathrm{O}_{2}$ for enhancing PDT efficacy, resulting in the increased intracellular ROS for accelerating apoptosis of cancer cells. Fourthly, $\mathrm{As} / \mathrm{As}_{x} \mathrm{O}_{y}$ NSs exhibit unique anti-tumor property through inactivating some main anti-oxidants and anti-oxidases to cut off the "retreat routes" of ROS, and by damaging MMP. Last but not least, the inherent outstanding fluorescence imaging ability of $\mathrm{As} / \mathrm{As}_{x} \mathrm{O}_{y} \mathrm{NSs}$ endows them as in vivo imaging agents. In line of the remarkable biocompatibility and biodegradability, As/ $\mathrm{As}_{x} \mathrm{O}_{y}$ NSs present good totipotency and versatility, endowing them with great potential in clinical application value and prospect.

In conclusion, our work presents a means of creating a nanomedicine based on 2D As/ $\mathrm{As}_{x} \mathrm{O}_{y} @ \mathrm{PDA} @ \mathrm{M}$ NSs capable of multiple independently targeted ROS bursts and a powerful capacity for tumor inhibition. The $\mathrm{As}_{x} \mathrm{O}_{y}$ indirectly induces the 
Heart
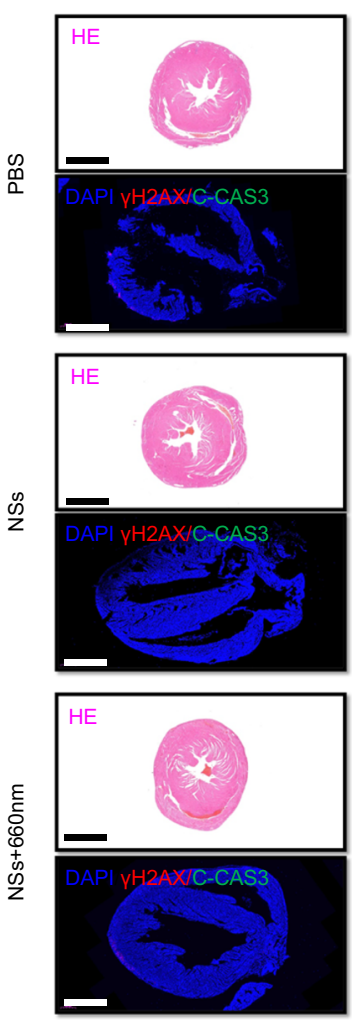

PBS

b
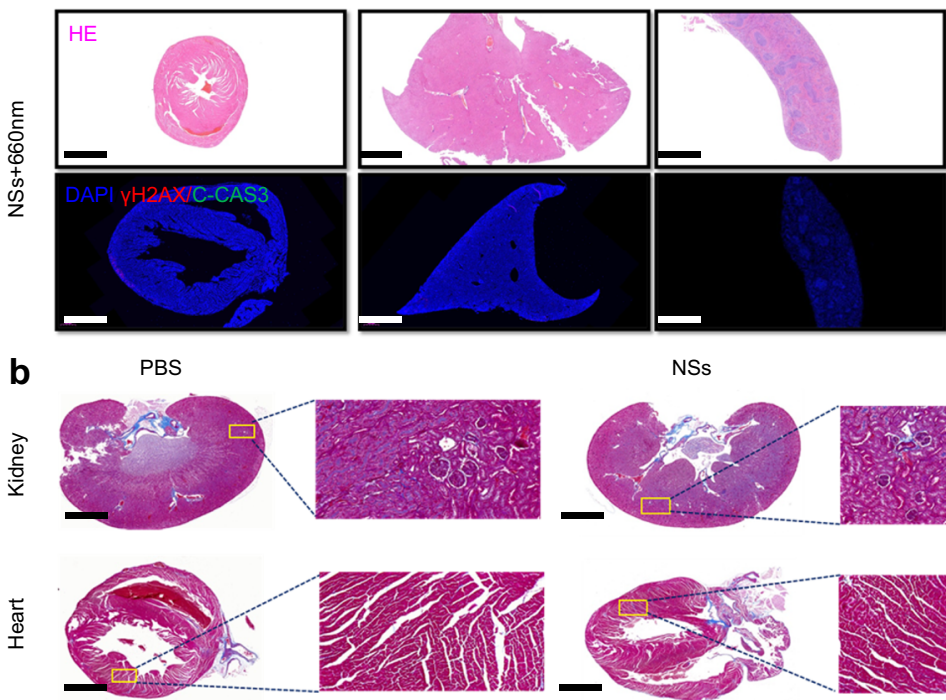

NS
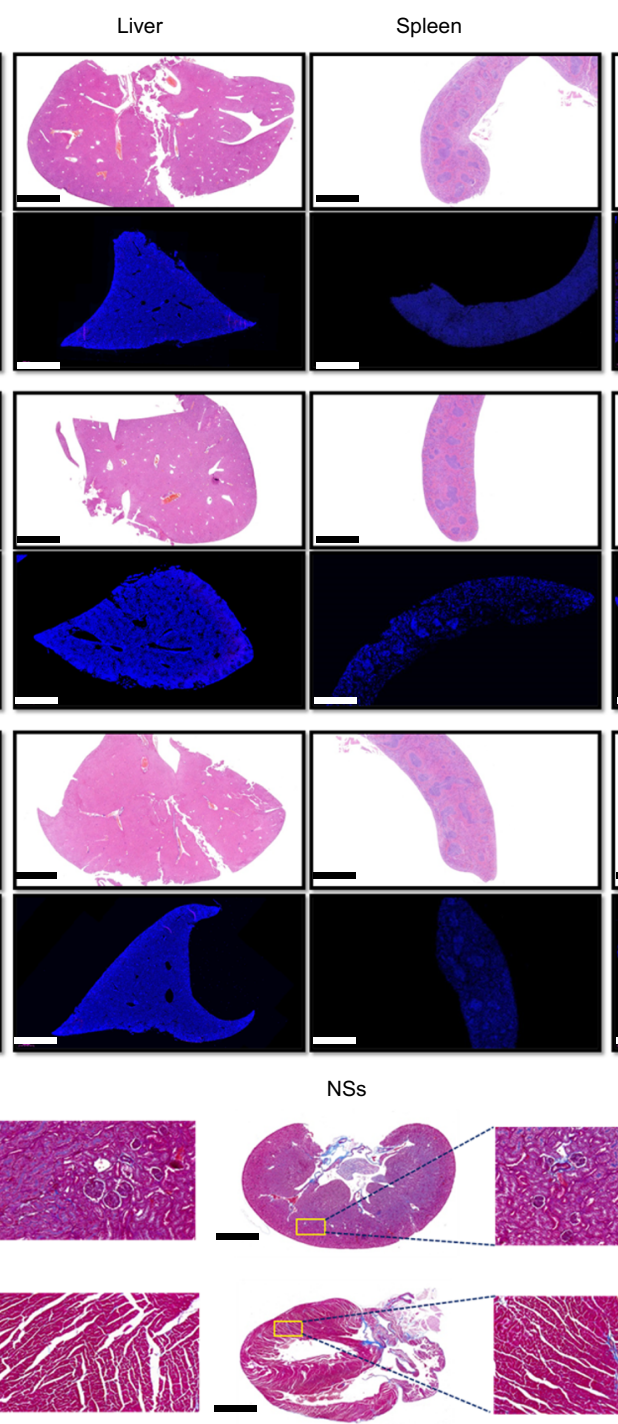
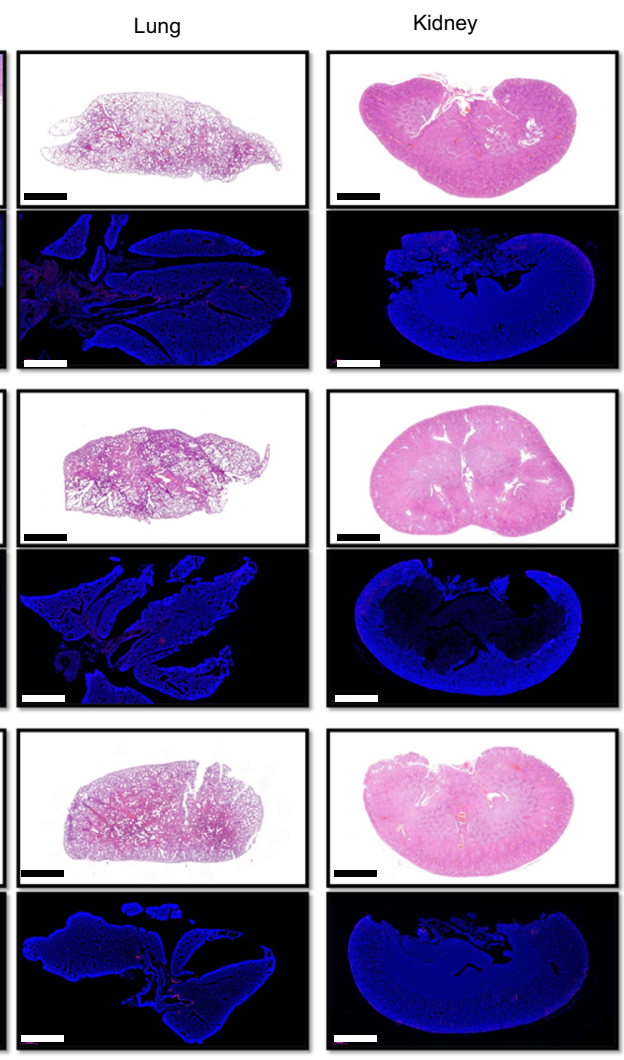

NSs+660nm
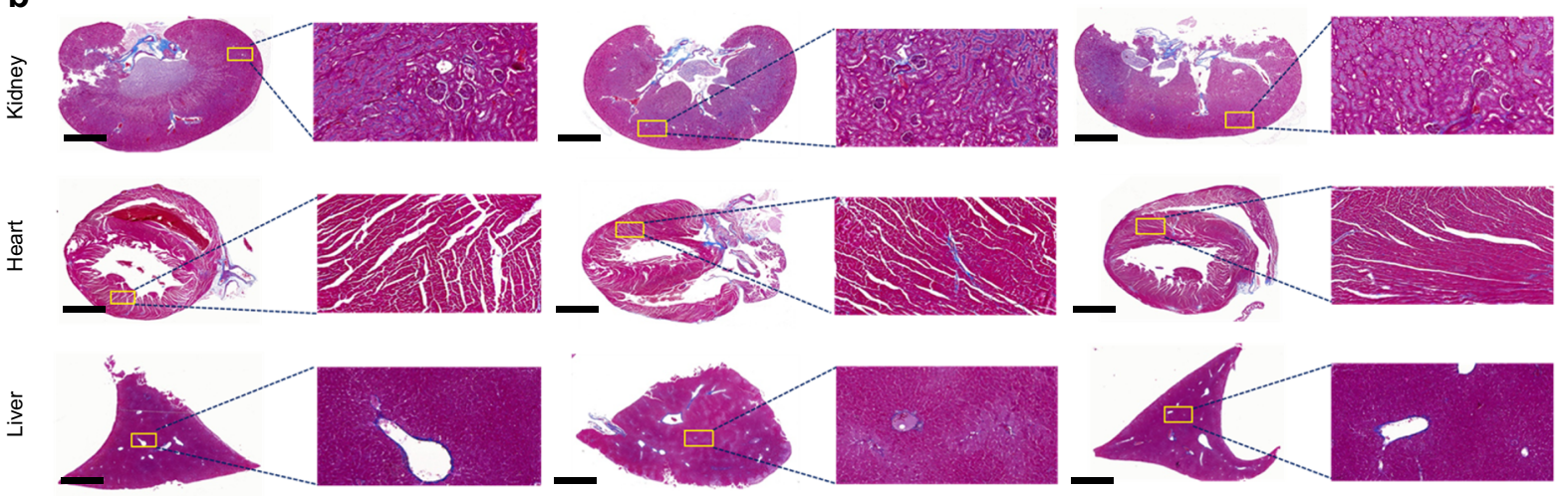

C

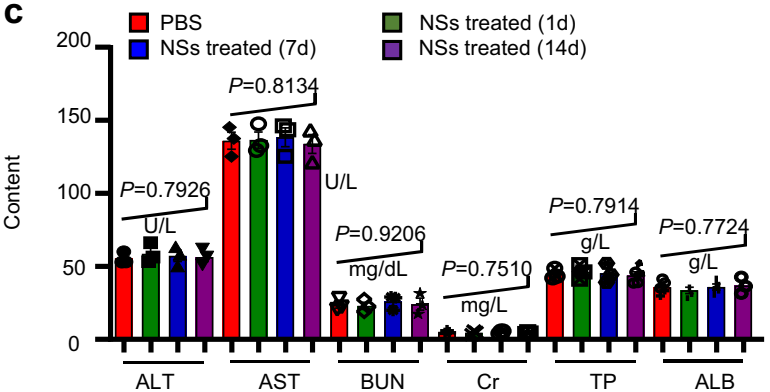

accumulation of intracellular ROS content by inactivating some main anti-oxidants and anti-oxidases to cut off the "retreat routes" of ROS. As acted as an efficient photosensitizer to catalyze the generation of ${ }^{1} \mathrm{O}_{2}$ from $\mathrm{O}_{2}$ when exposed to the $660 \mathrm{~nm}$ laser, directly improving the intracellular ROS content. According to the band structure of As and $\mathrm{As}_{x} \mathrm{O}_{y}$, a promising Type II heterojunction was formed. Thus, the electrons in the $\mathrm{CB}$ of As preferred to transfer to the $\mathrm{CB}$ of $\mathrm{As}_{x} \mathrm{O}_{y}$. At the same time, the

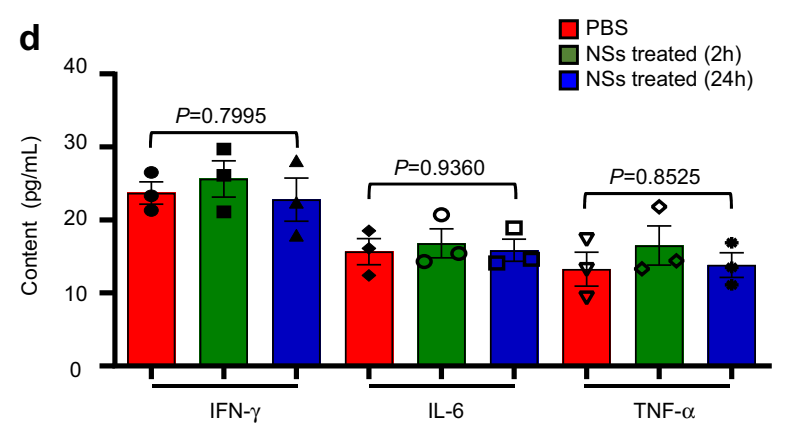

holes in the $\mathrm{VB}$ of $\mathrm{As}_{x} \mathrm{O}_{y}$ preferred to transfer to the $\mathrm{VB}$ of As, contributing to thoroughly separate photo-excited charges in the $\mathrm{CB}$ and $\mathrm{VB}$ of two different photosensitizers, further catalyzing the reduction of $\mathrm{O}_{2}$ to generate $\cdot \mathrm{O}_{2}^{-}$and oxidation of GSH to inhibit the antioxidant ability of cancer cells. As a consequence, the efficient photo-excited charge separation in the $\mathrm{As} / \mathrm{As}_{x} \mathrm{O}_{y}$ NSs-based Type II heterojunction can enhance the intracellular ROS content in both direct and indirect ways. The abundant 
Fig. 10 Biocompatibility evaluation of As/As $\mathbf{O}_{\mathbf{y}} @$ PDA@M NSs. a H\&E staining and immunofluorescence (IF) staining in sections from major organs after different treatments with PBS, NSs, or NSs $+660 \mathrm{~nm}$ laser irradiation (irradiation performed only within tumor areas). The nucleus was stained by DAPI (blue), damaged DNA by $\gamma \mathrm{H} 2 \mathrm{AX}$ foci (red), and apoptotic cells by apoptosis marker C-CAS3 (green). Scale bars $=1000 \mu \mathrm{m}$. b Masson staining of pathological fibrous deposition in main organs (kidney, heart, and liver) from mice treated with PBS, NSs, or NSs $+660 \mathrm{~nm}$ laser irradiation (irradiations performed only within tumor areas). Scale bars $=1000 \mu \mathrm{m}$. c Blood biochemistry and hematology analysis of Balb/c mice treated with As/ $\mathrm{As}_{x} \mathrm{O}_{y} @ \mathrm{PDA} @ \mathrm{M}$ NSs.d Serum levels IFN- $\gamma, \mathrm{IL}-6$, and TNF- $\alpha$ in healthy mice at 2 or $24 \mathrm{~h}$ post intravenous injection of PBS or As/As $\mathrm{O}_{y} @ P D A @ M$ NSs. Error bars $=$ standard deviation $(n=3), n=3$ biologically independent mice. For all statistical analysis, data are presented as mean values \pm SEM. Twosided ANOVAs were performed for all other comparisons. No adjustments were made for multiple comparisons. For the H\&E staining, IF staining, and Masson staining, three times each experiment was repeated independently with similar results.

oxygen vacancies on the surface of $\mathrm{As} / \mathrm{As}_{x} \mathrm{O}_{y}$ NSs can catalyze a Fenton-like reaction to generate $\cdot \mathrm{OH}$ and $\mathrm{O}_{2}$ from $\mathrm{H}_{2} \mathrm{O}_{2}$, which can not only directly promote ROS burst but also essentially enhance the PDT effect. Additionally, after surface engineering with PDA and $\mathrm{M}$ shells, the produced As/ $\mathrm{As}_{x} \mathrm{O}_{y} @ \mathrm{PDA} @ \mathrm{M}$ Ns not only possess remarkable biocompatibility with no long-term safety concerns in vivo, but also enhance the accumulation in tumors with homologous targeting ability to mediate high photothermal conversion efficiency under laser irradiation. The inherent outstanding fluorescence imaging ability of As/ $\mathrm{As}_{x} \mathrm{O}_{y} @ \mathrm{PDA} @ \mathrm{M}$ Ns further demonstrate the imaging-guided therapeutic performance both in vitro and in vivo. Therefore, such an unprecedented type II heterojunction successfully induces a ROS burst in cancer cells and integrates imaging-guided chemo/photothermal/photodynamic therapies, establishing a paradigm for cancer therapy with high efficacy therapeutic efficacy and high biocompatibility.

\section{Methods}

Materials. Bulk arsenic was purchased from Sigma-Aldrich and stored in the dark with argon protection. Human normal liver cells (HL-7702), human embryonic kidney 293 (HEK293), human non-small cell lung cancer (A549), and human breast cancer cell (MCF-7) were obtained from ATCC. DPBF, MB, $\mathrm{H}_{2} \mathrm{O}_{2}(30 \%)$, glutathione, and N-methyl-pyrrolidone (NMP) were purchased from SigmaAldrich. RPMI 1640 medium, Dulbecco's modified Eagle medium (DMEM), PBS, fetal bovine serum (FBS) and trypsin-EDTA were purchased from Gibco Life Technologies. Primary antibodies: Phospho-Histone H2A.X (Ser139) (D7T2V), Cell Signaling (Product \# 80312), Dilution 1:200; C-CAS3 (Asp175) (5A1E), Cell Signaling (Product \# 9664), Dilution 1:250. Secondary antibodies: Anti-Rabbit IgG $(\mathrm{H}+\mathrm{L})$ Highly Cross-Adsorbed Secondary Antibody, Alexa Fluor 488, ThermoFisher (Catalog \# A-11034), Dilution 1:1000; Anti-Mouse IgG $(\mathrm{H}+\mathrm{L})$ Highly Cross-Adsorbed Secondary Antibody, Alexa Fluor 647, ThermoFisher (Catalog \# A-21236), Dilution 1:1000

Characterization. The morphology and thickness of NSs was assessed by transmission electron microscopy (TEM, JEM-2100UHR, JEOL, Japan) and atomicforce microscopy (AFM, FASTSCANBIO, Germany). Dynamic light scattering (DLS) was applied to study the size and zeta potential of NSs. XPS (ESCALAB 250Xi, Japan) and energy-dispersive X-ray spectroscopy (EDS) (Inca X-MAX, Oxford, UK) were used to detect NSs's chemical constituents. The chemical structures were studied by Bruker D8 multipurpose XRD. The Infinite M200 PRO spectrophotometer was used to study the UV-Vis-NIR spectra. The electronic spin resonance (ESR) spectrum was employed to detect ROS radicals.

Preparation of cancer cell membrane fragments. Cells were first incubated in culture dishes $(10.0 \mathrm{~cm}$ in diameter), then detached with a cell scraper and followed by centrifugation at $700 \times g$ for $5 \mathrm{~min}$. Cells were collected and resuspended in the cold PBS buffer, followed by centrifugation at $600 \times \mathrm{g}$ for $5 \mathrm{~min}$ to obtain cell pellets. The cell pellets were incubated with a hypotonic lysing buffer consisting of phenylmethanesulfonyl fluoride (PMSF) (Beyotime Institute of Biotechnology) and membrane protein extraction reagent in an ice bath for $10-15 \mathrm{~min}$. Using a freeze-thaw method, cells were then broken repeatedly at $700 \times g$ for $10 \mathrm{~min}$ at $4^{\circ}$ C. The supernatant was further centrifuged at $14,000 \times g$ for $30 \mathrm{~min}$ to collect the cell membrane fragments and lyophilized overnight. The final materials were stored at $-80^{\circ} \mathrm{C}$ and rehydrated in ultra-pure water or PBS buffer before use.

Synthesis of As/As $\mathbf{O}_{\boldsymbol{y}} @$ @DAAM NSs. As/As $\mathrm{O}_{y}$ NSs were synthesized by ballmilling and probe sonication-assisted liquid exfoliation. First, $1 \mathrm{~g}$ of As was dispersed in $80 \mathrm{~mL} \mathrm{NMP}$ and ground by ball milling at $800 \mathrm{rpm}$ for $30 \mathrm{~min}$. Then the mixture was sonicated for $10 \mathrm{~h}$ in NMP. Finally, the solution was centrifuged at
$1006 \times g$ for 5 min to obtain As/As $\mathrm{O}_{y}$ NSs, which were stored at $4{ }^{\circ} \mathrm{C}$. For the PDA coating, the resulting As/ $\mathrm{As}_{\mathrm{x}} \mathrm{O}_{\mathrm{y}} \mathrm{NSs}$ were dispersed in $10 \mathrm{~mL}$ of Tris buffer $(\mathrm{pH} 8.5$ $\left.10 \times 10^{-3} \mathrm{M}\right)$ containing dopamine hydrochloride $(10 \mathrm{mg})$, and the above mixture was rotated for $4 \mathrm{~h}$ at room temperature in darkness to obtain PDA-coated As/ $\mathrm{As}_{x} \mathrm{O}_{y}$ NSs (As/As $\mathrm{O}_{y} @ \mathrm{PDA} \mathrm{NSs}$ ). For the cancer cell membrane coating, the As/ $\mathrm{As}_{x} \mathrm{O}_{y} @ \mathrm{PDA}$ NSs were added into $10 \mathrm{~mL}$ of PBS containing cancer cell membrane at room temperature. Sonication was applied for $1 \mathrm{~h}$ to obtain cancer cell membrane-coated As/Ass $\mathrm{O}_{y} @ \mathrm{PDA} N \mathrm{Ns}$ (As/As $\mathrm{O}_{y} @ \mathrm{PDA} @ \mathrm{M} \mathrm{NSs}$ ).

Photothermal conversion and stability. $1 \mathrm{~mL}$ of As/As $\mathrm{O}_{y} @ \mathrm{PDA} @ \mathrm{M}$ NSs solution at different concentrations $(10,50$, and 100) were irradiated by an $808 \mathrm{~nm}$ laser with different power density $\left(0.5,1\right.$, and $\left.2 \mathrm{~W} / \mathrm{cm}^{2}\right)$ for $5 \mathrm{~min}$. The temperature of the As/As $\mathrm{O}_{y} @ \mathrm{PDA} @ \mathrm{M}$ NSs solution was recorded every $30 \mathrm{~s}$ by an IR thermal camera. The stability of As/As $\mathrm{O}_{y}$ NSs and As/As $\mathrm{O}_{y} @ P D A @ M ~ N S s$ was investigated by evaluating their absorption and photothermal performance. First, As/ $\mathrm{As}_{x} \mathrm{O}_{y} \mathrm{NSs}$ or As/As $\mathrm{O}_{y} @ \mathrm{PDA} @ \mathrm{M}$ NSs were dispersed in $\mathrm{PBS}(\mathrm{pH}=7.4)$ solution Then, their absorption and photothermal performance were detected at predetermined time intervals to characterize the stability of $\mathrm{As} / \mathrm{As}_{x} \mathrm{O}_{y} \mathrm{NSs}$ and As/ $\mathrm{As}_{x} \mathrm{O}_{y} @ \mathrm{PDA} @ \mathrm{M}$ NSs.

Biocompatibility and cytotoxicity. Normal cells (HL-7702 and HEK 293) and cancer cells (A549 and MCF-7) were seeded in 96-well plates $\left(37^{\circ} \mathrm{C}, 5 \% \mathrm{CO}_{2}\right)$ and cultured for $24 \mathrm{~h}$. The culture medium was then replaced with new fresh culture medium containing $\mathrm{As} / \mathrm{As}_{x} \mathrm{O}_{y} \mathrm{NSs}$ at different concentrations $(0.5,1,5$, and $10 \mu \mathrm{g} /$ $\mathrm{mL}$ ) and incubated for another $24 \mathrm{~h}$. 3-(4,5-dimethylthiazol-2-yl)-2,5-diphenyltetrazolium bromide (MTT) assay was used to determine cell viability.

Cellular uptake. The uptake efficacy of $\mathrm{As} / \mathrm{As}_{x} \mathrm{O}_{y} \mathrm{NSs}, \mathrm{As} / \mathrm{As} \mathrm{O}_{x} \mathrm{O}_{y} @ \mathrm{PDA}$ NSs, and As/As $\mathrm{O}_{y} @ \mathrm{PDA} @ \mathrm{M}$ NSs was studied. $5 \times 10^{4} \mathrm{MCF}-7$ cells were incubated in glassbottomed dishes $\left(1.5 \mathrm{~mL}\right.$ of cell culture medium) for $12 \mathrm{~h}\left(37^{\circ} \mathrm{C}, 5 \% \mathrm{CO}_{2}\right)$. Then the As $/ \mathrm{As}_{x} \mathrm{O}_{y} \mathrm{NSs}, \mathrm{As} / \mathrm{As}_{x} \mathrm{O}_{y} @ \mathrm{PDA} \mathrm{NSs}$, or As/As $\mathrm{O}_{y} @ \mathrm{PDA} @ \mathrm{M}$ NSs were added with an As dose of $5 \mu \mathrm{g} / \mathrm{mL}$. After incubation for $4 \mathrm{~h}$, cells were rinsed carefully with PBS twice and fixed by paraformaldehyde (4\%) for $15 \mathrm{~min}$. Then the cells were washed with PBS twice and incubated with $500 \mu \mathrm{L}$ of Hoechst 33342 fluorescent dye for $30 \mathrm{~min}$. Finally, confocal laser scanning microscopy (CLSM) was applied for fluorescent imaging. Hoechst 33342 was excited at $350 \mathrm{~nm}$, while As/As ${ }_{x} \mathrm{O}_{\mathrm{y}} \mathrm{NSs}$ were excited at $400 \mathrm{~nm}$.

ROS production and GSH consumption in vitro. 1, 3-diphenylisobenzofuran (DPBF) was applied to assess the ability of $\mathrm{As} / \mathrm{As}_{x} \mathrm{O}_{y} @ \mathrm{PDA} @ \mathrm{M}$ NSs to generate $\mathrm{O}_{2}{ }^{-}$and ${ }^{1} \mathrm{O}_{2}$. In brief, As/As $\mathrm{O}_{y} @$ PDA@M NSs were mixed with DPBF $(1 \mathrm{~mL}, 1$ $\mathrm{mM}$ ) at a final volume of $3 \mathrm{~mL}$. The final concentrations of As/As $\mathrm{O}_{y} @ \mathrm{PDA} @ \mathrm{M}$ NSs were 5,10 , and $15 \mu \mathrm{g} / \mathrm{mL}$. The mixture was agitated in dark for $1 \mathrm{~h}$ to reach a balance of desorption and adsorption. Then a $660 \mathrm{~nm}$ laser $\left(0.3 \mathrm{~W} / \mathrm{cm}^{2}\right)$ was applied to irradiate the reaction solution. The concentration of DPBF was measured by the UV-Vis spectrophotometer. A GSH assay kit was employed to measure the consumption of GSH under the same conditions. The $\cdot \mathrm{OH}$ generation of As/As $x$ O @PDA@M NSs was determined by MB. Briefly, As/As $\mathrm{O}_{y} @ \mathrm{PDA} @ \mathrm{M}$ NSs suspension was mixed with $\mathrm{MB}$ and $\mathrm{H}_{2} \mathrm{O}_{2}$ in PBS, with final concentrations of As/As $\mathrm{O}_{y} @ \mathrm{PDA} @ \mathrm{M}$ NSs being 5, 10, or $15 \mu \mathrm{g} / \mathrm{mL}$. The absorbance of MB was recorded by UV-vis-NIR after different time intervals.

ROS production in cells. The ROS production was detected by DCFH-DA. Briefly, MCF-7 cells were cultured in dishes for $24 \mathrm{~h}\left(37^{\circ} \mathrm{C}, 5 \% \mathrm{CO}_{2}\right)$. Then, fresh medium containing As/As $\mathrm{O}_{y} @ \mathrm{PDA} @ \mathrm{M}$ NSs was added to replace the original medium, and cells were allowed to culture for another $12 \mathrm{~h}$. After that, the DCFH-DA solution $(0.2 \mathrm{mM})$ was added and cells were cultured for $0.5 \mathrm{~h}$ and washed by PBS three times. Finally, cells were exposed to a $660 \mathrm{~nm}$ laser $\left(0.3 \mathrm{~W} / \mathrm{cm}^{2}\right)$ for $10 \mathrm{~min}$, with green fluorescence imaged by CLSM indicating the generation of ROS.

In vitro therapy with As/As $\mathbf{O}_{\mathbf{y}} @$ PDA@M NSs. A549 and MCF-7 cells were seeded and cultured in 96 -well plates $\left(37^{\circ} \mathrm{C}, 5 \% \mathrm{CO}_{2}\right)$. After $24 \mathrm{~h}$, medium was discarded and fresh medium containing As/As $\mathrm{O}_{y} @ \mathrm{PDA} @ \mathrm{M}$ NSs $(0.5,1,5$, and 10 $\mu \mathrm{g} / \mathrm{mL}$ ) was added for another $12 \mathrm{~h}$ incubation. Then cells were washed with PBS 
and irradiated by a $660 \mathrm{~nm}$ laser $\left(0.3 \mathrm{~W} / \mathrm{cm}^{2}\right)$ or an $808 \mathrm{~nm}$ laser $\left(1.0 \mathrm{~W} / \mathrm{cm}^{2}\right)$ in fresh medium for $10 \mathrm{~min}$. After incubation for $12 \mathrm{~h}$, PBS was used to wash the cells three times, and the MTT assay was used to assess cell viability.

Animals. All animals received humane care, and the Animal Ethics Committee of the National Institute of Radiological Sciences approved all the animal experiments. All experiments were carried out according to the recommendations of the Committee for the Care and Use of Laboratory Animals, Tianjin University. The cages were placed in conventional rooms with controlled photoperiod (07:00-19:00 h white light, $\pm 200 \mathrm{~lx}$ at $1 \mathrm{~m}$ above the floor; 19:00-07:00 $\mathrm{h}$ red light, $\pm 5 \mathrm{~lx}$ at $1 \mathrm{~m})$, temperature $\left(20-22^{\circ} \mathrm{C}\right)$, relative humidity $(50-60 \%)$, and ventilation (15 air changes $\left.\mathrm{h}^{-1}\right)$.

Pharmacokinetic study. C57BL/6 mice were administered As/As $\mathrm{O}_{y} @ \mathrm{PDA} @ \mathrm{M}$ NSs $(200 \mu \mathrm{L}, 2 \mathrm{mg} / \mathrm{kg})$ via intravenous (i.v.) injection. $20 \mathrm{~mL}$ blood sample was collected to study the fluorescence of $\operatorname{As} / \mathrm{As}_{x} \mathrm{O}_{y}$ NSs at various lengths.

Xenograft tumor model. To build the xenograft tumor model, $200 \mu \mathrm{L}$ MCF-7 cells $\left(2 \times 10^{6}\right.$ cells $)$ were subcutaneously injected into naked $\mathrm{Balb} / \mathrm{c}$ mice to obtain a tumor volume of $\sim 100 \mathrm{~mm}^{3}$ (calculated as tumor length $\times$ tumor width $\times$ tumor width/2) for the following experiments.

In vivo biodistribution and fluorescence imaging study. As/ $\mathrm{As}_{x} \mathrm{O}_{y} @ \mathrm{PDA} @ \mathrm{M}$ NSs were i.v. injected into tumor-bearing mice, and the fluorescence was measured by the Maestro2 In-Vivo Imaging System. At $24 \mathrm{~h}$ post-injection, tumor and major organs were collected and the concentration of As/As $\mathrm{O}_{x} @ \mathrm{PDA} @ \mathrm{M} \mathrm{NSs}$ accumulated in tumor and major organs was quantified by the fluorescence intensity.

In vivo therapy of As/As $\mathbf{O}_{\mathbf{y}} @ \mathbf{P D A} @ \mathbf{M}$ NSs. Thirty tumor-bearing mice were randomly divided into six groups for different treatments ${ }^{50,51}$. G1: saline as control group, G2: 808 and $660 \mathrm{~nm}$ laser irradiation, G3: As/ $\mathrm{As}_{x} \mathrm{O}_{y} @ \mathrm{PDA} @ \mathrm{M} \mathrm{NSs}(2 \mathrm{mg} /$ $\mathrm{kg}), \mathrm{G} 4: \mathrm{As} / \mathrm{As}_{x} \mathrm{O}_{y} @ \mathrm{PDA} @ \mathrm{M}$ NSs with $808 \mathrm{~nm}$ laser $\left(1.0 \mathrm{~W} / \mathrm{cm}^{2}\right)$, G5: As/ $\mathrm{As}_{x} \mathrm{O}_{y} @ \mathrm{PDA} @ \mathrm{M}$ NSs with $660 \mathrm{~nm}$ laser $\left(0.3 \mathrm{~W} / \mathrm{cm}^{2}\right)$, and G6: As/As $\mathrm{O}_{y} @ \mathrm{PDA} @ \mathrm{M}$ NSs with 660 and $808 \mathrm{~nm}$ laser irradiation. The tumor volume was recorded every two days during the course of study of 14 days.

In vivo toxicity. $\mathrm{C} 57 \mathrm{BL} / 6$ mice were i.v. injected with $\mathrm{As} / \mathrm{As}_{x} \mathrm{O}_{y} @ \mathrm{PDA} @ \mathrm{M} \mathrm{NSs}(5$ $\mathrm{mg} / \mathrm{kg}$ ). Blood samples were collected to measure interleukin6 (IL-6), tumor necrosis factor- $\alpha$ (TNF- $\alpha$ ), and interferon- $\gamma$ (IFN- $\gamma)$ by ELISA at 12 and $24 \mathrm{~h}$ postinjection. At days 1, 7, and 14, albumin (ALB), aspartate ALT, AST, BUN, creatinine $(\mathrm{Cr})$, and TP were measured via a complete blood panel test. For in vivo toxicity, mice were sacrificed to obtain their main organs for eosin (H\&E) and hematoxylin staining after 30 days.

Statistical analysis. Analysis of flow cytometry data was performed with Flowjo v7.6 software. Graph Pad Prism (8.0) and Origin 9.0 were used for data statistics and statistical significance calculation. Microsoft Excel 2016 was used for biodistribution and tumor size analysis. FL images were analyzed using Image J 1.8.0. Zetasizer Nano software v3.30 for analyses of particle size. TEM data was analyzed using Gatan-DigitalMicrograph-3.9. AFM data was analyzed using NanoScope Analysis 1.8. Statistical analysis was performed using the Student's $t$-test with statistical significance assigned at ${ }^{*} P<0.05$ (significant), ${ }^{*} P<0.01$ (moderately significant), ${ }^{* * *} P<0.001$ (highly significant), and ${ }^{* * * *} P<0.0001$ (extremely significant).

Reporting summary. Further information on research design is available in the Nature Research Reporting Summary linked to this article.

\section{Data availability}

The authors declare that all data supporting the findings of this study are available within the article and the Supplementary Information. Other data are available from the corresponding authors upon reasonable request.

Received: 10 January 2021; Accepted: 11 June 2021; Published online: 06 August 2021

\section{References}

1. Sies, H. \& Jones, D. P. Reactive oxygen species (ROS) as pleiotropic physiological signalling agents. Nat. Rev. Mol. Cell Biol. 21, 363-383 (2020).

2. D'Autréaux, B. \& Toledano, M. B. ROS as signalling molecules: mechanisms that generate specificity in ROS homeostasis. Nat. Rev. Mol. Cell Biol. 8, 813-824 (2007).
3. Dickinson, B. C. \& Chang, C. J. Chemistry and biology of reactive oxygen species in signaling or stress responses. Nat. Chem. Biol. 7, 504-511 (2011).

4. Nathan, C. \& Cunningham-Bussel, A. Beyond oxidative stress: an immunologist's guide to reactive oxygen species. Nat. Rev. Immunol. 13, 349-361 (2013)

5. Shadel, G. S. \& Horvath, T. L. Horvath, mitochondrial ROS signaling in organismal homeostasis. Cell 163, 560-569 (2015).

6. Dixon, S. J. \& Stockwell, B. R. The role of iron and reactive oxygen species in cell death. Nat. Chem. Biol. 10, 9-17 (2014).

7. Zhou, Z., Song, J., Nie, L. \& Chen, X. Reactive oxygen species generating systems meeting challenges of photodynamic cancer therapy. Chem. Soc. Rev. 45, 6597-6626 (2016).

8. Trachootham, D., Alexandre, J. \& Huang, P. Targeting cancer cells by ROSmediated mechanisms: a radical therapeutic approach? Nat. Rev. Drug Discov. 8, 579-591 (2009).

9. Son, S. et al. Multifunctional sonosensitizers in sonodynamic cancer therapy. Chem. Soc. Rev. 49, 3244-3261 (2020).

10. Li, X., Lee, S. \& Yoon, J. Supramolecular photosensitizers rejuvenate photodynamic therapy. Chem. Soc. Rev. 47, 1174-1188 (2018).

11. Yang, B., Chen, Y. \& Shi, J. Reactive Oxygen Species (ROS)-based nanomedicine. Chem. Rev. 119, 4881-4985 (2019).

12. Chimene, D., Alge, D. L. \& Gaharwar, A. K. Two-dimensional nanomaterials for biomedical applications: emerging trends and future prospects. $A d v$. Mater. 27, 7261-7284 (2015).

13. Tan, C. et al. Recent advances in ultrathin two-dimensional nanomaterials. Chem. Rev. 117, 6225-6331 (2017).

14. Chen, Y. et al. Two-dimensional metal nanomaterials: synthesis, properties, and applications. Chem. Rev. 118, 6409-6455 (2018).

15. Tao, W. et al. Emerging two-dimensional monoelemental materials (Xenes) for biomedical applications. Chem. Soc. Rev. 48, 2891-2912 (2019).

16. Xiaoyuan, J. L. et al. Capturing functional two-dimensional nanosheets from sandwich-structure vermiculite for cancer theranostics. Nat. Commun. 12, 1124, https://doi.org/10.1038/s41467-021-21436-5 (2021).

17. Ping, G. Y. et al. Biomedical applications of $2 \mathrm{D}$ monoelemental materials formed by group VA and VIA: a concise review. J. Nanobiotechnology 19, 96 https://doi.org/10.1186/s12951-021-00825-4 (2021).

18. Tao, W. et al. Antimonene quantum dots: synthesis and application as nearinfrared photothermal agents for effective cancer therapy. Angew. Chem. Int Ed. 56, 11896-11900 (2017).

19. Ji, X. et al. A novel top-down synthesis of ultrathin $2 \mathrm{D}$ boron nanosheets for multimodal imaging-guided cancer therapy. Adv. Mater. 30, 1803031 (2018).

20. Tao, W. et al. Two-dimensional antimonene-based photonic nanomedicine for cancer theranostics. Adv. Mater. 30, 1802061 (2018).

21. Ouyang, J. et al. 2D Monoelemental germanene quantum dots: synthesis as robust photothermal agents for photonic cancer nanomedicine. Angew. Chem. Int. Ed. 58, 13405-13410 (2019).

22. Tao, W. et al. Black phosphorus nanosheets as a robust delivery platform for cancer theranostics. Adv. Mater. 29, 1603276 (2017).

23. Jiang, O. X. et al. In situ sprayed NIR-responsive analgesic black phosphorusbased gel for diabetic ulcer treatment. Proc. National Academy Sci. 117, 28667-28677, https://doi.org/10.1073/pnas.2016268117 (2020).

24. Feng, C. et al. Germanene-based theranostic materials for surgical adjuvant treatment: inhibiting tumor recurrence and wound infection. Matter 3 , 127-144 (2020).

25. Jiang, O. C. et al. Black Phosphorus in Biological Applications: Evolutionary Journey from Monoelemental Materials to Composite Materials. Accounts of Materials Research 2, 489-500, https://doi.org/10.1021/accountsmr.1c00039 (2021).

26. Zhang, S., Yan, Z., Li, Y., Chen, Z. \& Zeng, H. Atomically thin arsenene and antimonene: semimetal-semiconductor and indirect-direct band-gap transitions. Angew. Chem. Int. Ed. 54, 3112-3115 (2015).

27. Zhang, S. et al. Recent progress in $2 \mathrm{D}$ group-VA semiconductors: from theory to experiment. Chem. Soc. Rev. 47, 982-1021 (2018).

28. Zhang, S. et al. Semiconducting group 15 monolayers: a broad range of band gaps and high carrier mobilities. Angew. Chem. Int. Ed. 55, 1666-1669 (2016).

29. Pumera, M. \& Sofer, Z. 2D Monoelemental arsenene, antimonene, and bismuthene: beyond black phosphorus. Adv. Mater. 29, 1605299 (2017).

30. Chuang, L. S. et al. Arsenene Nanodots with Selective Killing Effects and their Low-Dose Combination with B-Elemene for Cancer Therapy. Advanced Materials 33, 2102054 https://doi.org/10.1002/adma.202102054 (2021).

31. Chuang, L. J. et al. Pnictogens in medicinal chemistry: evolution from erstwhile drugs to emerging layered photonic nanomedicine. Chemical Society Reviews 50, 2260-2279, https://doi.org/10.1039/D0CS01175D (2021).

32. Wang, X. et al. Arsenene: a potential therapeutic agent for acute promyelocytic leukaemia cells by acting on nuclear proteins. Angew. Chem. Int. Ed. 59, 5151-5158 (2020).

33. Zhu, H. H. et al. Oral arsenic plus retinoic acid versus intravenous arsenic plus retinoic acid for non-high-risk acute promyelocytic leukaemia: a noninferiority, randomised phase 3 trial. Lancet Oncol. 19, 871-879 (2018). 
34. Zhu, H. H., Hu, J., Lo-Coco, F. \& Jin, J. The simpler, the better: oral arsenic for acute promyelocytic leukemia. Blood 134, 597-605 (2019).

35. Gilliam, S. J. et al. Raman spectroscopy of arsenolite: crystalline cubic As4O6. J. Solid State Chem. 173, 54-58 (2003)

36. Gusmão, R., Sofer, Z., Bouša, D. \& Pumera, M. Pnictogen (As, Sb, Bi) nanosheets for electrochemical applications are produced by shear exfoliation using kitchen blenders. Angew. Chem. Int. Ed. 56, 14417-14422 (2017).

37. Geng, $\mathrm{Z}$. et al. Oxygen vacancies in $\mathrm{ZnO}$ nanosheets enhance $\mathrm{CO}_{2}$ electrochemical reduction to CO. Angew. Chem. Int. Ed. 57, 6054-6059 (2018).

38. $\mathrm{Xu}, \mathrm{W}$. J. et al. Porous cobalt oxide nanoplates enriched with oxygen vacancies for oxygen evolution reaction. Nano Energy 43, 110-116 (2018).

39. Pan, C. et al. Z-Scheme heterojunction functionalized pyrite nanosheets for modulating tumor microenvironment and strengthening photo/ chemodynamic therapeutic effects. Adv. Funct. Mater. 30, 1906466 (2019).

40. Ou, M. et al. Two-dimensional highly oxidized ilmenite nanosheets equipped with Z-scheme heterojunction for regulating tumor microenvironment and enhancing reactive oxygen species generation. Chem. Eng. J. 390, 124524 (2020).

41. Zhang, H. et al. SnTe@ $\mathrm{MnO}_{2}$-SP nanosheet-based intelligent nanoplatform for second near-infrared light-mediated cancer theranostics. Adv. Funct. Mater. 29, 1903791 (2019).

42. Zeng, W. et al. Dual-response oxygen-generating $\mathrm{MnO}_{2}$ nanoparticles with polydopamine modification for combined photothermal-photodynamic therapy. Chem. Eng. J. 389, 124494 (2020).

43. Fang, R. H., Kroll, A. V., Gao, W. \& Zhang, L. Cell membrane coating nanotechnology. Adv. Mater. 30, 1706759 (2018).

44. Jeanne, M. et al. PML/RARA oxidation and arsenic binding initiate the antileukemia response of $\mathrm{As}_{2} \mathrm{O}_{3}$. Cancer Cell 18, 88-98 (2010).

45. Li, X., Lovell, J. F., Yoon, J. \& Chen, X. Clinical development and potential of photothermal and photodynamic therapies for cancer. Nat. Rev. Clin. Oncol. 17, 657-674 (2020).

46. Dröge, W. Free radicals in the physiological control of cell function. Physiol. Rev. 82, 47-95 (2002).

47. Kong, N. et al. ROS-mediated selective killing effect of black phosphorus: mechanistic understanding and its guidance for safe biomedical applications. Nano Lett. 20, 3943-3955 (2020).

48. Chen, W. et al. Black phosphorus nanosheet-based drug delivery system for synergistic photodynamic/photothermal/chemotherapy of cancer. Adv. Mater. 29, 1603864 (2017).

49. Wang, H. et al. Ultrathin black phosphorus nanosheets for efficient singlet oxygen generation. J. Am. Chem. Soc. 137, 11376-11382 (2015).

50. Zhang, C. et al. Semiconducting polymer nano-PROTACs for activatable photo-immunometabolic cancer therapy. Nat. Commun. 12, 2934 (2021).

51. Zhao, B. et al. Photocatalysis-mediated drug-free sustainable cancer therapy using nanocatalyst. Nat. Commun. 12, 1345 (2021).

\section{Acknowledgements}

We acknowledge the supports from National Natural Science Foundation of China (Grant Nos. 81801826, 32071322; to X.J.), the US METAvivor Early Career Investigator Award (No. 2018A020560; to W.T.), Harvard Medical School/Brigham and Women's
Hospital Department of Anesthesiology Basic Scientist Grant (No. 2420 BPA075; to W.T.) and Center for Nanomedicine Research Fund (No. 2019A014810; to W.T.). W.T. is a recipient of the Khoury Innovation Award (No. 2020A003219), Gillian Reny Stepping Strong Center for Trauma Innovation Breakthrough Innovator Award (No. 113548), and American Heart Association (AHA) Collaborative Science Award (No. 2018A004190). W.T. also received a start-up package (for 3 years) from the Department of Anesthesiology, Perioperative and Pain Medicine to establish his independent research laboratory at Harvard Medical School and Brigham and Women's Hospital.

\section{Author contributions}

X.J. and W.T. designed and supervised the project. X.J. and L.M. designed the experimental strategies. X.J., N.K., and H.Z. performed the experiments and analyzed the data N.K. wrote and improved the manuscript with contributions from C.F., C.L., Y.X., and $\mathrm{X}$ Z. W.T. and J.S.K. provided conceptual advice and revised the manuscript. All the authors contributed to the proof reading and corrections of the manuscript.

\section{Competing interests}

The authors declare no competing interests.

\section{Additional information}

Supplementary information The online version contains supplementary material available at https://doi.org/10.1038/s41467-021-24961-5.

Correspondence and requests for materials should be addressed to W.T. or X.J.

Peer review information Nature Communications thanks Liang Cheng and the other anonymous reviewers for their contribution to the peer review of this work.

Reprints and permission information is available at http://www.nature.com/reprints

Publisher's note Springer Nature remains neutral with regard to jurisdictional claims in published maps and institutional affiliations.

\begin{abstract}
Open Access This article is licensed under a Creative Commons BY Attribution 4.0 International License, which permits use, sharing,
adaptation, distribution and reproduction in any medium or format, as long as you give appropriate credit to the original author(s) and the source, provide a link to the Creative Commons license, and indicate if changes were made. The images or other third party material in this article are included in the article's Creative Commons license, unless indicated otherwise in a credit line to the material. If material is not included in the article's Creative Commons license and your intended use is not permitted by statutory regulation or exceeds the permitted use, you will need to obtain permission directly from the copyright holder. To view a copy of this license, visit http://creativecommons.org/ licenses/by/4.0/.
\end{abstract}

(C) The Author(s) 2021 